\title{
Analysis of Gas Membrane Ultra-High Purification of Small Quantities of Mono- Isotopic Silane
}

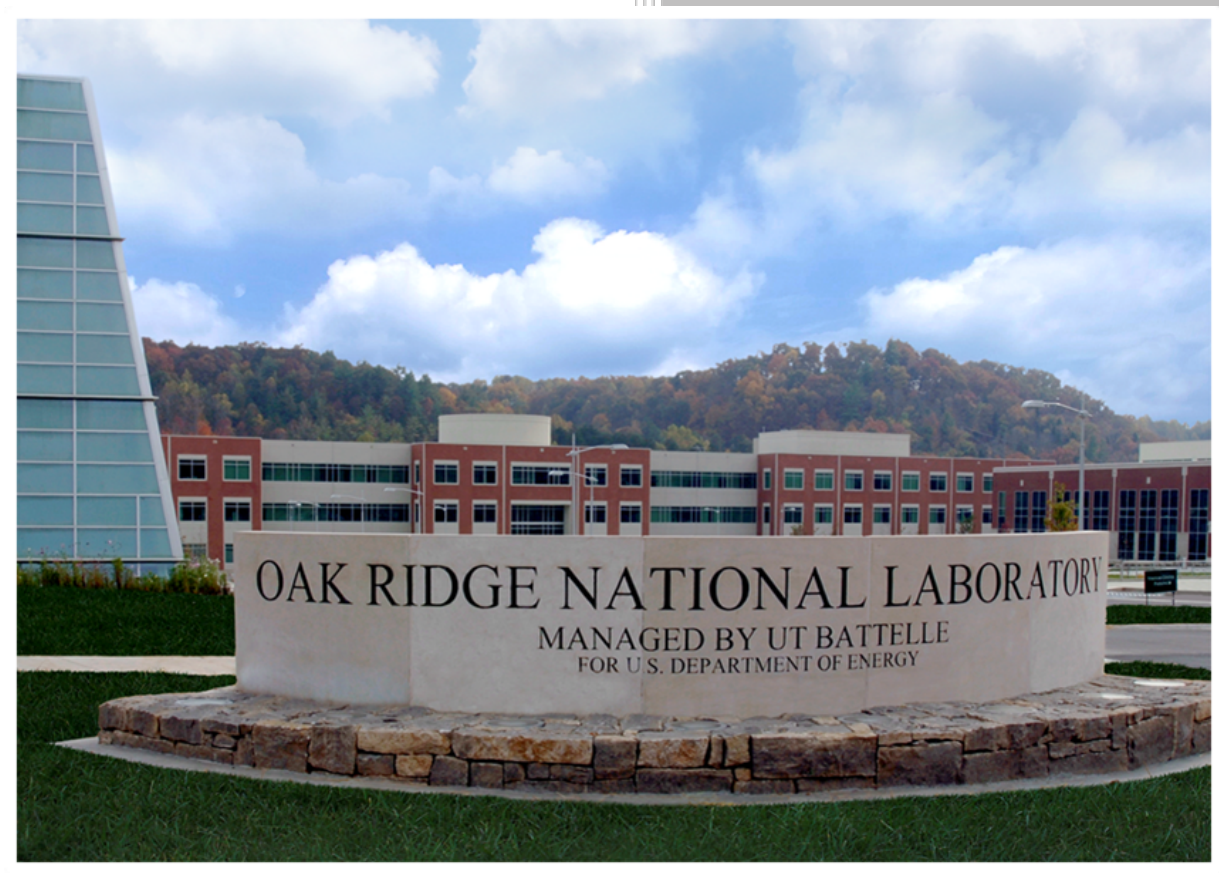

Approved for public release. Distribution is unlimited.

Valmor F. de Almeida Kevin J. Hart

05 September 2016 


\title{
DOCUMENT AVAILABILITY
}

Reports produced after January 1, 1996, are generally available free via US Department of Energy (DOE) SciTech Connect.

Website http://www.osti.gov/scitech/

Reports produced before January 1, 1996, may be purchased by members of the public from the following source:

\author{
National Technical Information Service \\ 5285 Port Royal Road \\ Springfield, VA 22161 \\ Telephone 703-605-6000 (1-800-553-6847) \\ TDD 703-487-4639 \\ Fax 703-605-6900 \\ E-mail info@ntis.gov \\ Website http://www.ntis.gov/help/ordermethods.aspx
}

Reports are available to DOE employees, DOE contractors, Energy Technology Data Exchange representatives, and International Nuclear Information System representatives from the following source:

Office of Scientific and Technical Information

PO Box 62

Oak Ridge, TN 37831

Telephone 865-576-8401

Fax 865-576-5728

E-mail reports@osti.gov

Website http://www.osti.gov/contact.html

This report was prepared as an account of work sponsored by an agency of the United States Government. Neither the United States Government nor any agency thereof, nor any of their employees, makes any warranty, express or implied, or assumes any legal liability or responsibility for the accuracy, completeness, or usefulness of any information, apparatus, product, or process disclosed, or represents that its use would not infringe privately owned rights. Reference herein to any specific commercial product, process, or service by trade name, trademark, manufacturer, or otherwise, does not necessarily constitute or imply its endorsement, recommendation, or favoring by the United States Government or any agency thereof. The views and opinions of authors expressed herein do not necessarily state or reflect those of the United States Government or any agency thereof. 
Chemical Sciences Division

\section{Analysis of Gas Membrane Ultra-High Purification of Small Quantities of Mono-Isotopic Silane}

Valmor F. de Almeida, and Kevin J. Hart

05 September 2016

Prepared by

OAK RIDGE NATIONAL LABORATORY

Oak Ridge, TN 37831-6283

managed by

UT-BATTELLE, LLC

for the

US DEPARTMENT OF ENERGY

under contract DE-AC05-00OR22725 


\title{
Analysis of Gas Membrane Ultra-High Purification of Small Quantities of Mono-Isotopic Silane*
}

\author{
Valmor F. de Almeida and Kevin J. Hart \\ Chemical Sciences Division \\ OAK Ridge National Laboratory \\ OAK RIDGE, TN 37831-6119, USA
}

Technical Report ORNL/TM-2016/278

This manuscript has been authored by UT-Battelle, LLC under Contract No. DE-AC05-000R22725 with the U.S. Department of Energy. The United States Government retains a non-exclusive, paid-up, irrevocable, world-wide license to publish or reproduce the published form of this manuscript, or allow others to do so, for United States Government purposes. The Department of Energy will provide public access to these results of federally sponsored research in accordance with the DOE Public Access Plan (http://energy.gov/downloads/doe-public-access-plan).

05 September 2016

*Also available by request to dealmeidav@ornl.gov 


\begin{abstract}
A small quantity of high-value, crude, mono-isotopic silane is a prospective gas for a small-scale, high-recovery, ultra-high membrane purification process. This is an unusual application of gas membrane separation for which we provide a comprehensive analysis of a simple purification model. The goal is to develop direct analytic expressions for estimating the feasibility and efficiency of the method, and guide process design; this is only possible for binary mixtures of silane in the dilute limit which is a somewhat realistic case. Among the common impurities in crude silane, methane poses a special membrane separation challenge since it is chemically similar to silane. Other potential problematic surprises are: ethylene, diborane and ethane (in this order). Nevertheless, we demonstrate, theoretically, that a carefully designed membrane system may be able to purify mono-isotopic, crude silane to electronics-grade level in a reasonable amount of time and expenses. We advocate a combination of membrane materials that preferentially reject heavy impurities based on mobility selectivity, and light impurities based on solubility selectivity. We provide estimates for the purification of significant contaminants of interest. To improve the separation selectivity, it is advantageous to use a permeate chamber under vacuum, however this also requires greater control of in-leakage of impurities in the system. In this study, we suggest cellulose acetate and polydimethylsiloxane as examples of membrane materials on the basis of limited permeability data found in the open literature. We provide estimates on the membrane area needed and priming volume of the cell enclosure for fabrication purposes when using the suggested membrane materials. These estimates are largely theoretical in view of the absence of reliable experimental data for the permeability of silane. Last but not least, future extension of this work to the non-dilute limit may apply to the recovery of silane from rejected streams of natural silicon semi-conductor processes.
\end{abstract}




\section{Contents}

\begin{tabular}{ll}
\hline List of figures & 1
\end{tabular}

List of tables 1

\begin{tabular}{lll}
\hline 1 & Introduction & 2
\end{tabular}

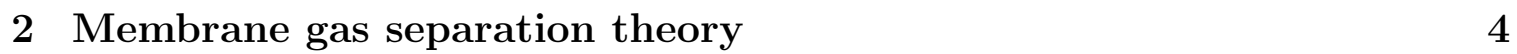

2.1 Binary gas mixture in the dilute limit . . . . . . . . . . . . . . 4

2.2 Slow-permeant impurity depletion (permeate recirculation) . 12

2.3 Fast-permeant impurity depletion (retentate recirculation) . 17

$\begin{array}{lll}3 & \text { Results } & 22\end{array}$

3.1 Slow-permeant impurity depletion . . . . . . . . . . . . . . . 26

3.1 .1 Single-cycle results . . . . . . . . . . . . . . . . . . . . 27

3.1.2 Multi-cycle results . . . . . . . . . . . . . . . . . . . . . 27

3.2 Fast-permeant impurity depletion . . . . . . . . . . . . . . . . . 31

3.3 Multi-stage system . . . . . . . . . . . . . . . . . . . . . . . . . . 35

3.4 Finishing comments . . . . . . . . . . . . . . . . . . . . . . 37

\begin{tabular}{|ll}
\hline 4 Conclusions & 37
\end{tabular}

\begin{tabular}{|ll}
\hline Acknowledgments & 38
\end{tabular}

\begin{tabular}{|ll|}
\hline A Appendix: Supporting information & 39
\end{tabular}

\begin{tabular}{ll}
\hline References & 40
\end{tabular} 


\section{List of Figures}

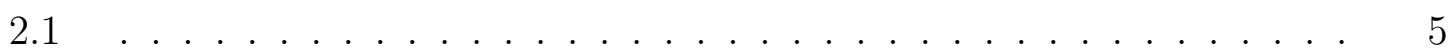

$2.2 \quad$ Fast-permeant impurity depletion loop . . . . . . . . . . . . . . . . . 7

2.3 Slow-permeant impurity depletion loop . . . . . . . . . . . . . . . . . 13

$2.4 \quad$ Fast-permeant impurity depletion loop . . . . . . . . . . . . . . . . . 19

3.1 Multi-stage impurity depletion sequence . . . . . . . . . . . . . 36

\section{List of Tables}

1.1 Typical impurity tolerances for electronics-grade silane product . . . 2

3.1 Pure-component, $a$, permeability constant, $\mathscr{P}_{a}$, of silane and impurities in a PDMS membrane ................... 23

3.2 Pure-component, $a$, permeance, $\overline{\mathscr{P}}_{a}$, of silane and impurities in a CA

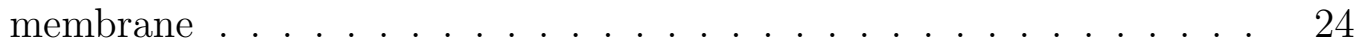

3.3 Lennard-Jones force potential intermolecular distance parameter from viscosity data . . . . . . . . . . . . . . . . . . 25

3.4 Single-cycle performance quantities for slow-permeant impurity depletion loop using a PDMS membrane . . . . . . . . . . . . . . . . 28

3.5 Multi-cycle performance quantities for slow-permeant impurity depletion loop using a PDMS membrane . . . . . . . . . . . . . . . . . 30

3.6 Single-cycle performance quantities for fast-permeant impurity depletion loop using a CA membrane . . . . . . . . . . . . . . . . . . . 31

3.7 Single-cycle performance quantities for fast-permeant impurity depletion loop using a PDMS membrane . . . . . . . . . . . . . . . . . 33

3.8 Single-cycle performance quantities for fast-permeant impurity depletion loop using a PDMS membrane (continued) . . . . . . . . . . . . 34 


\section{Introduction}

ONO-ISOTOPIC silane is produced in small quantities, at very high cost, for future

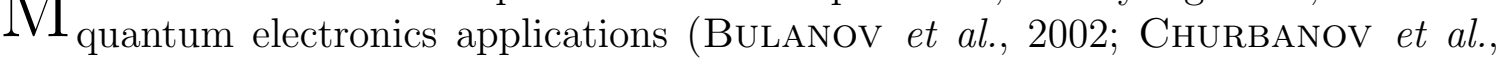
2010; DEVYATYKH et al., 2003; ITOH et al., 2003). This opens a new door for a post-synthesis membrane purification approach as compared to large-scale, industrial cryogenic distillation of natural silane (LORENZ, 1983). In particular, gas separation membranes (HSIEH AND KELLER II, 1992; VOROTYNTSEV et al., 2008, 2013) have been studied for related applications but no detailed analytic bounds have been provided to guide the practical implementation of real processes.

We demonstrate theoretically that typical tolerances on impurity content (table 1.1 in electronics-grade silane may be met via post-synthesis gas membrane purification within reasonable operation conditions. This study derives explicit mathematical expressions for estimating values of operation parameters involved in a compact membrane separation loop.

Table 1.1: Typical impurity tolerances for electronics-grade silane product (99.998 vol\% purity) as measured in part per million by volume.

\begin{tabular}{|cc|cc|}
\hline Gas & {$[\mathrm{ppm}(\mathrm{v})]$} & & \multicolumn{2}{c|}{ Gas $[\mathrm{ppm}(\mathrm{v})]$} \\
\cline { 5 - 5 } $\mathrm{CO}_{2}$ & 0.05 & $\mathrm{CO}$ & 0.08 \\
Disilane $\mathrm{Si}_{2} \mathrm{H}_{6}$ & 0.5 & $\mathrm{He}$ & 1.0 \\
$\mathrm{H}_{2}$ & 20 & $\mathrm{~N}_{2}$ & 0.5 \\
$\mathrm{O}_{2}+\mathrm{Ar}$ & 0.06 & $\mathrm{CH}_{4}$ & 0.04 \\
$\mathrm{HC}\left(\mathrm{C}_{2}-\mathrm{C}_{4}\right)$ & 0.1 & $\mathrm{SiF}_{4}$ & 1.0 \\
Disiloxane $\mathrm{Si}_{2} \mathrm{H}_{6} \mathrm{O}$ & 0.05 & $\mathrm{~B}_{2} \mathrm{H}_{6}$ & 0.02 \\
$\mathrm{AsH}_{3}$ & 0.05 & $\mathrm{PH}_{3}$ & 0.02 \\
& & &
\end{tabular}

Membrane separations are becoming competitive, in terms of robustness and cost, to traditional separation processes such as distillation and adsorption. In the recent past, various commercial options for membrane materials have become available, in particular for gas separation applications. Membrane separation can significantly reduce the purification effort of silane by allowing for easy of implementation and safety controls as compared to other competitive methods.

Organic, inorganic, and hybrid membranes are commercially available as of today; they can also be passive or reactive membranes. Despite recent advances, measurements of silane permeability in membrane materials, in the presence of contaminants, have not been made with sufficient rigor to be used in membrane module design. Predictive methods to estimate permeability of gases in various polymer membrane 
materials is a promising complementary alternative but still depend on a database of experimental data (ALENTIEV et al., 2013; RYZHIKH et al., 2015), therefore at the moment there is scarce information on the permeability of silanes and other similar compounds of interest such as germanes.

Recent pertinent work (VOROTYNTSEV et al. 2013) suggests that the permeability of silane (table 3.1), with typical impurities, in commercial polydimethylsiloxane (PDMS) allows for separation of impurities of interest. Alternatively, limited data for silane separation from hydrogen (HSIEH AND KELLER II, 1992) indicates that the potential difficulty of separating hydrogen from silane on a solubility-selective PDMS material can be overcome with a sieve-selective, rigid cellulose acetate (CA) material. We are left with making conjectures about the potential problem of separating methane from silane. The single data set at hand (VOROTYNTSEV et al., 2013) indicates a problematic situation since solubility appears to be similar for both compounds and therefore potential poor separation ability. We were unable to find data on size-based separation membranes. The molecular diameters of methane and silane do differ, hence we expect to see differences in polymer diffusion characteristics but at this point it is uncertain whether size alone could be enough to allow for a sufficiently large separation factor. Nevertheless, we present estimates based on the results of (HSIEH AND KELLER II, 1992) that seem promising for resolving the methane separation problem and making the purification of silane practical.

Our present work uses current data found in the open literature to analyze conditions for successful gas membrane separations. The data at hand (table 3.1) indicate that the slower permeants, $\mathrm{CH}_{4}, \mathrm{H}_{2}, \mathrm{Ar}, \mathrm{O}_{2}$, and $\mathrm{He}$, and the faster permeants, $\mathrm{C}_{2} \mathrm{H}_{6}$, $\mathrm{B}_{2} \mathrm{H}_{6}$, and $\mathrm{C}_{2} \mathrm{H}_{4}$, present a potential difficulty for separation with PDMS. This study attempts to clarify the conditions under which separation is challenging and propose alternate conditions for effective separation. The impurities in the silane gas can be slower or faster permeates than silane, therefore it is productive to design a system that takes into consideration where the permeate and retentate streams go. We designed two flow schemes, as in VOROTYNTSEV et al. (2008), and will refer to them as the slow-permeant impurity depletion loop (permeate recirculation) and the fastpermeant impurity depletion loop (retentate recirculation) (figs. 2.3 and 2.4). Each loop consists of a feed tank and an impurity storage tank. The basic idea is to build a multi-stage membrane separation process by recirculating (MAJUMDAR et al., 1987) either the permeate or the retentate stream (fig. 2.3 and fig. 2.4 respectively) into the feed tank. The recirculation is typically quite high to enable high purification; in other words, the stage cut, $\theta$, is near unit (uncommon on large-scale industrial applications but applicable for our case). A pre-specified amount to be withdrawn from the feed tank, $\lambda$, at a particular rate, largely determines the time taken for the purification operation. 


\section{Membrane gas separation theory}

Crude silane gas is a mixture of many species, denoted $a=1, \ldots, \mathcal{A}$, with a relatively high content of the primary product, $\mathrm{SiH}_{4}$, say, $95 \%$ by mass. In dense rubbery or rigid membranes, sorption-diffusion is the dominant process by which a gas species traverses the membrane. A simple continuum level of theory for the trans-membrane molar flux $\left(\operatorname{mol~m}^{-2} \mathrm{~s}^{-1}\right), N_{a}$, of the $\boldsymbol{a}$-th gas species, at a point $\boldsymbol{x}$ at time $t$, on a membrane surface (fig. 2.1) is built around the concept of a permeability constant, $\mathscr{P}_{a}$, the thickness of the membrane, $h$, and the partial pressures on each side of the membrane

$$
N_{a}(\boldsymbol{x}, t):=\frac{\mathscr{P}_{a}}{h}\left(x_{a} p^{(\mathrm{F})}-y_{a} p^{(\mathrm{P})}\right), \quad a=1, \ldots, \mathcal{A},
$$

where $x_{a}(\boldsymbol{x}, t)$ denotes the ath species molar fraction field on the feed side, $y_{a}(\boldsymbol{x}, t)$ denotes the ath species molar fraction field on the permeate side, and the $p^{(\cdot)}(\boldsymbol{x}, t)$ is the gas pressure field. The superscripts $(\mathrm{P})$ and $(\mathrm{F})$ stand for the permeate side of the membrane and feed side, respectively. The permeability constant is not really a constant and depends significantly on temperature. For complex cases, it may also depend on the species concentration in the polymer when plasticization occurs during gas diffusion. The permeability constant is a combination of sorption and diffusion. Hence the underlying multi-species equilibrium and transport phenomena can be intricate and depart significantly from (2.1). Nevertheless, from (2.1), the separation principle hinges on the flux ratio of a rapidly permeating species as compared to a slower permeant

$$
\frac{N_{a}(\boldsymbol{x}, t)}{N_{b}(\boldsymbol{x}, t)}=\alpha_{a, b}^{*} \frac{\left(x_{a}-y_{a} p_{\mathrm{R}}\right)}{\left(x_{b}-y_{b} p_{\mathrm{R}}\right)},
$$

where $p_{\mathrm{R}}(\boldsymbol{x}, t):=p^{(P)} / p^{(F)}$ is the pressure ratio. Equation 2.2 demonstrates that at a vacuum condition in the permeate side $\left(p_{\mathrm{R}} \approx 0\right)$, the flux ratio does not depend on pressure and it depends linearly on the mole fraction ratio $x_{a} / x_{b}$ on the feed side of the membrane.

\subsection{Binary gas mixture in the dilute limit}

Further progress in obtaining closed formulae can only be made for a binary system, $\mathcal{A}=2$, where one of the species is dilute. This situation fits well the silane purification process with one impurity species, and the predominant $\mathrm{SiH}_{4}$ species if the other impurity components do not cross couple in the diffusion process.

In the absence of boundary layer effects, surface resistances, and a sweep gas in the permeate side, 2.1 defines the concentration of the gas in the permeate side 


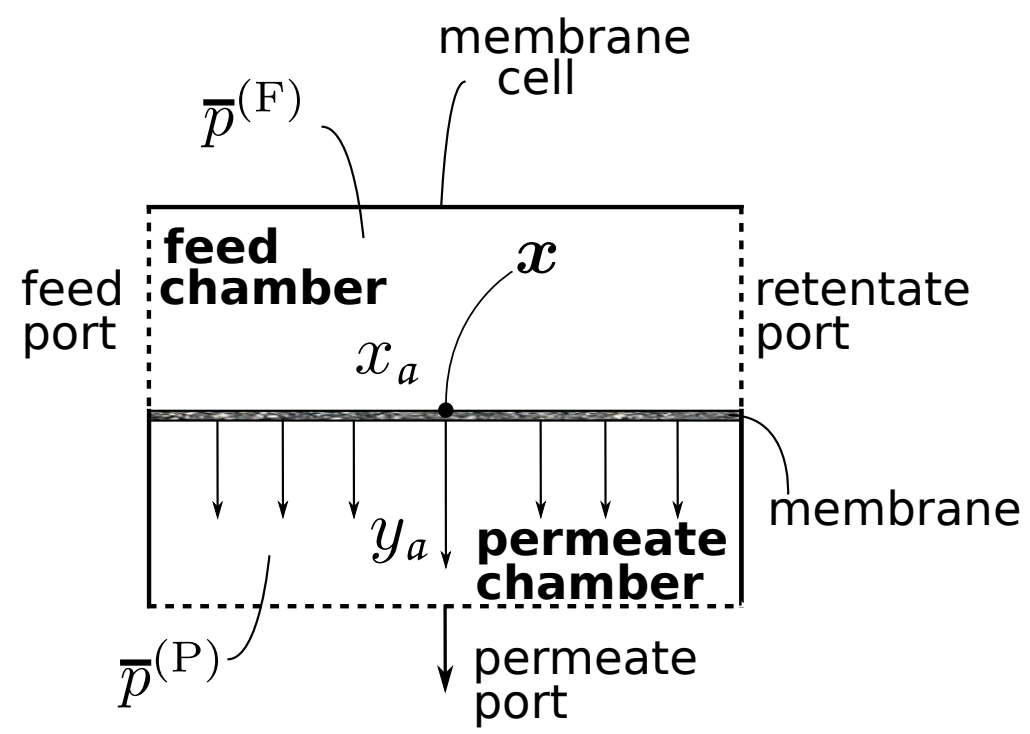

Fig. 2.1: Membrane sorption-diffusion transport.

given known conditions in the feed side and the permeate pressure, thus

$$
\frac{N_{a}(\boldsymbol{x}, t)}{N_{b}(\boldsymbol{x}, t)}=\frac{y_{a}}{y_{b}} .
$$

Therefore, denoting the local, effective, separation factor of a binary gas mixture

$$
\alpha_{a, b}(\boldsymbol{x}, t):=\frac{y_{a} / x_{a}}{y_{b} / x_{b}}
$$

and using the binary ideal separation factor, $\alpha_{a, b}^{*}:=\frac{\mathscr{P}_{a}}{\mathscr{P}_{b}}$, in the molar flux ratios 2.2 and 2.3 , one arrives at the local quadratic equation for $\alpha_{a, b}(\boldsymbol{x}, t)$

$$
x_{a} \alpha_{a, b}^{2}+\left(p_{\mathrm{R}}\left(\alpha_{a, b}^{*}-1\right)-x_{a}\left(\alpha_{a, b}^{*}+1\right)+1\right) \alpha_{a, b}+\alpha_{a, b}^{*}\left(x_{a}-1\right)=0,
$$

where $x_{a}+x_{b}=1$. We consider $\alpha_{a, b}^{*}$ to be the ratio of permeability coefficients measured on a dilute binary system. That is, the effect of plasticization, if any, is incorporated into the separation factor. The use of pure-component permeability data, as opposed to the binary counterpart, could result in erroneous separation factors because an impurity could permeate the membrane faster in a binary mixture than it would as a sole permeant. This error can be particularly disruptive when separating fast permeants from slow permeants in the a gas mixture. The underlying assumption in our analysis is that a dilute binary mixture will behave similarly to a dilute multicomponent mixture. 
Two limiting cases are of interest. First, the case of a dilute, slow-permeant impurity, namely, $x_{6} \ll 1$ ( or $x_{\mathrm{SiH}_{4}} \approx 1$ ), and $\alpha_{\mathrm{SiH}_{4}, 6}^{*}>1$, then using $a=\mathrm{SiH}_{4}$ in 2.5), it reduces to

$$
\alpha_{\mathrm{SiH}_{4}, 6}(\boldsymbol{x}, t)=\alpha_{\mathrm{SiH}_{4}, 6}^{*}-p_{\mathrm{R}}\left(\alpha_{\mathrm{SiH}_{4}, 6}^{*}-1\right),
$$

which unlike 2.5 is explicit for $\alpha_{\mathrm{SiH}_{4}, 6}$. Hence in a dilute binary gas mixture with a slow permeant impurity, the local separation factor (a transport property of the membrane for the mixture) of the predominant species relative to the impurity species is a linearly decaying function of the pressure ratio across the membrane. The maximum local separation factor is obtained at $p_{\mathrm{R}}=0$, that is, when the permeate side of the membrane is kept at a total vacuum, for any non-zero feed pressure.

The second case of interest, is when the impurity in the dilute binary mixture is a fast permeant, that is, $x_{a} \ll 1$ (or $x_{\mathrm{SiH}_{4}} \approx 1$ ), and $\alpha_{a, \mathrm{SiH}_{4}}^{*}>1$, then using $6=\mathrm{SiH}_{4}$ in 2.5 , gives

$$
\alpha_{a, \mathrm{SiH}_{4}}(\boldsymbol{x}, t)=\frac{\alpha_{a, \mathrm{SiH}_{4}}^{*}}{1+p_{\mathrm{R}}\left(\alpha_{a, \mathrm{SiH}_{4}}^{*}-1\right)},
$$

which unlike (2.6) is inversely proportional to the pressure ratio. Therefore it decays faster than the linear case (2.6) with increasing pressure ratio. While in both cases the maximum effective, local separation factor is the ideal separation factor when $p_{\mathrm{R}}=0$, the second case has a much more pronounced adverse effect of a non-zero pressure ratio. This lack of symmetry on the separation factor has been identified before (VOROTYNTSEV et al., 2008) as related to the fact that a faster permeant impurity accumulates more readily on the permeate side and the pressure $\bar{p}^{(\mathrm{P})}$ affects the partial pressure driving force of the impurity more intensely.

For future use, it is instructive to derive a relationship for the local molar fraction of the permeant species. In the case of a slow permeant impurity, using $(2.6),(2.4)$, $a=\mathrm{SiH}_{4}$, and $x_{\mathrm{SiH}_{4}} \approx 1$, to arrive at

$$
y_{6}(\boldsymbol{x}, t)=\frac{x_{6}}{\alpha_{\mathrm{SiH}_{4}, 6}^{*}-p_{\mathrm{R}}\left(\alpha_{\mathrm{SiH}_{4}, 6}^{*}-1\right)} .
$$

Similarly, the corresponding formula for a fast permeant impurity is obtained using $6=\mathrm{SiH}_{4}$ in 2.5), and (2.4) with the assumption $x_{\mathrm{SiH}_{4}} \approx 1$, thus

$$
y_{a}(\boldsymbol{x}, t)=\frac{\alpha_{a, \mathrm{SiH}_{4}}^{*} x_{a}}{1+p_{\mathrm{R}}\left(\alpha_{a, \mathrm{SiH}_{4}}^{*}-1\right)} .
$$

A simple analysis of the transport of a binary gas mixture through a membrane follows from assuming a crossflow condition in the feed chamber of the membrane cell (fig. 2.2), with a plug flow profile. Here the material balance on an element of fluid 


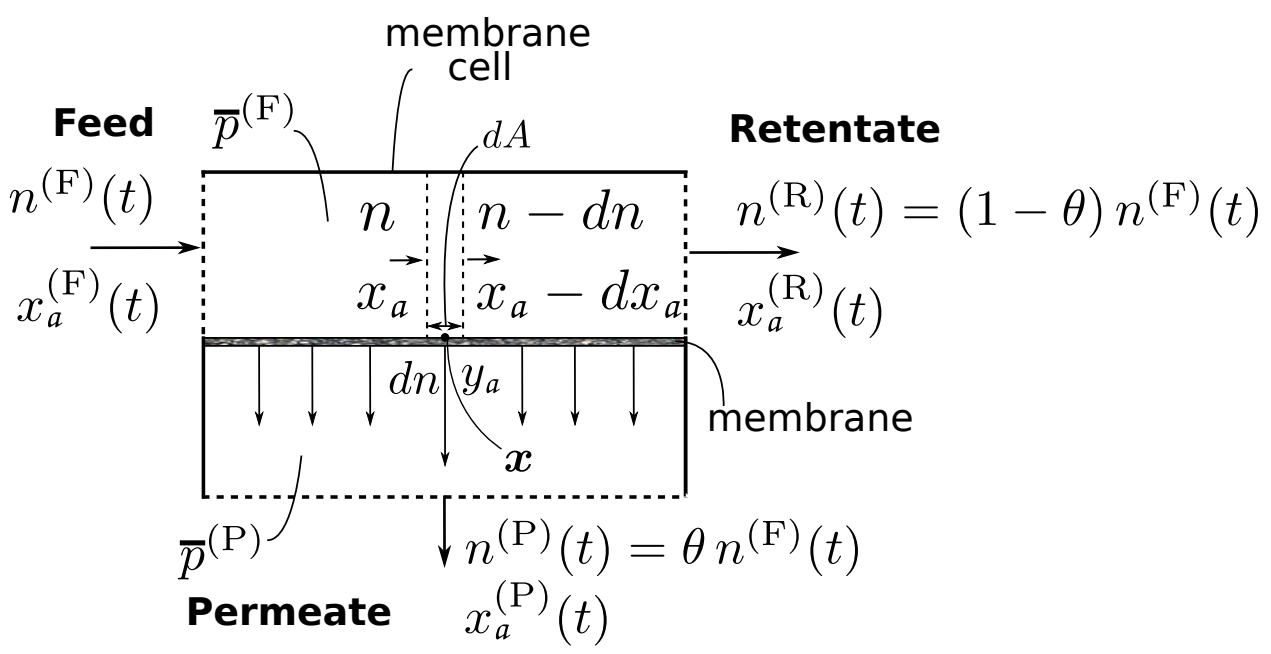

Fig. 2.2: Crossflow cell quantities.

for $\mathrm{SiH}_{4}$ in the feed chamber (fig. 2.2) is

$$
\left(x_{\mathrm{SiH}_{4}}-d x_{\mathrm{SiH}_{4}}\right)(n-d n)+y_{\mathrm{SiH}_{4}} d n-x_{\mathrm{SiH}_{4}} n=0,
$$

neglecting the higher-order term and rearranging the remaining terms results in

$$
\frac{d n}{n}=\frac{d x_{\mathrm{SiH}_{4}}}{y_{\mathrm{SiH}_{4}}-x_{\mathrm{SiH}_{4}}},
$$

where $n(\boldsymbol{x}, t)$ is the total molar flowrate $\left(\mathrm{mol} \mathrm{s}^{-1}\right)$ at point $\boldsymbol{x}$ on the membrane. Substitution of (2.4) in the above equation produces

$$
\frac{d n}{n}=\left[\frac{1+\left(\alpha_{\mathrm{SiH}_{4}, 6}-1\right) x_{\mathrm{SiH}_{4}}}{x_{\mathrm{SiH}_{4}}\left(\alpha_{\mathrm{SiH}_{4}, 6}-1\right)\left(1-x_{\mathrm{SiH}_{4}}\right)}\right] d x_{\mathrm{SiH}_{4}} .
$$

Assuming the effective separation factor of silane, $\alpha_{\mathrm{SiH}_{4}, 6}(\boldsymbol{x}, t)$, to be a spatial constant, $\bar{\alpha}_{\mathrm{SiH}_{4}, b}(t)$, over the whole membrane cell (a condition that can be somewhat satisfied for small trans-membrane pressures), 2.10 can be integrated from an arbitrary position along the membrane to the retentate outflow side of the cell (retentate port, fig. 2.1). That is, with some abuse of notation on the limits of integration, this integral

$$
\int_{n}^{n^{(\mathrm{R})}} \frac{d n}{n}=\int_{x_{\mathrm{SiH}_{4}}}^{x_{\mathrm{SiH}_{4}}^{(\mathrm{R})}}\left[\frac{1+\left(\bar{\alpha}_{\mathrm{SiH}_{4}, 6}-1\right) x_{\mathrm{SiH}_{4}}}{x_{\mathrm{SiH}_{4}}\left(\bar{\alpha}_{\mathrm{SiH}_{4}, 6}-1\right)\left(1-x_{\mathrm{SiH}_{4}}\right)}\right] d x_{\mathrm{SiH}_{4}},
$$


can be solved for as

$$
n(\boldsymbol{x}, t)=n^{(\mathrm{R})}\left[\left(\frac{x_{\mathrm{SiH}_{4}}(\boldsymbol{x}, t)}{x_{\mathrm{SiH}_{4}}^{(\mathrm{R})}}\right)^{\frac{1}{\alpha-1}} \times\left(\frac{1-x_{\mathrm{SiH}_{4}}^{(\mathrm{R})}}{1-x_{\mathrm{SiH}_{4}}(\boldsymbol{x}, t)}\right)^{\frac{\alpha}{\alpha-1}}\right],
$$

where for simplicity of notation we set

$$
\alpha:=\bar{\alpha}_{\mathrm{SiH}_{4}, 6}
$$

keeping in mind that this quantity is time-dependent through the pressure ratio in (2.6). The superscript $(\mathrm{R})$ indicates a quantity evaluated at the retentate outflow port position of the membrane cell, for instance, $x_{\mathrm{SiH}_{4}}^{(\mathrm{R})}:=x_{\mathrm{SiH}_{4}}\left(\boldsymbol{x}^{(\mathrm{R})}, t\right)$. Alternatively, (2.11) reads

$$
n(\boldsymbol{x}, t)=n^{(\mathrm{R})}\left[\left(\frac{1-x_{6}(\boldsymbol{x}, t)}{1-x_{b}^{(\mathrm{R})}}\right)^{\frac{1}{\alpha-1}}\left(\frac{x_{b}^{(\mathrm{R})}}{x_{6}(\boldsymbol{x}, t)}\right)^{\frac{\alpha}{\alpha-1}}\right],
$$

for the impurity species, which in the dilute limit $\left(x_{6} \ll 1\right)$ reduces to

$$
n(\boldsymbol{x}, t)=n^{(\mathrm{R})}\left[\left(\frac{x_{6}^{(\mathrm{R})}}{x_{6}(\boldsymbol{x}, t)}\right)^{\frac{\alpha}{\alpha-1}}\right] .
$$

The trans-membrane differential transport of the impurity is denoted by either,

$$
y_{6} d n=\frac{\mathscr{P}_{6}}{h}\left(x_{6} p^{(F)}-y_{6} p^{(P)}\right) d A,
$$

for a slow permeant impurity, or

$$
y_{a} d n=\frac{\mathscr{P}_{a}}{h}\left(x_{a} p^{(F)}-y_{a} p^{(P)}\right) d A,
$$

for a fast permeant impurity. In the dilute limit, use of 2.8 in 2.15 or 2.9 in 2.16 leads to the same result

$$
\begin{aligned}
d n & =\frac{\mathscr{P}_{6}}{h} \alpha_{\mathrm{SiH}_{4}, 6}^{*} \Delta p d A, \\
& =\frac{\mathscr{P}_{\mathrm{SiH}_{4}}}{h} \Delta p d A,
\end{aligned}
$$

where the average pressure drop is defined as $\Delta p(\boldsymbol{x}, t)=\bar{p}^{(\mathrm{F})}-\bar{p}^{(\mathrm{P})}$. Hence, $d n$ is primarily dominated by the permeability of the high-concentration species, which 
may be either the fast permeant component or the slow one. The molar flow rate differential, $d n$, can be obtained from (2.14) as

$$
d n=n^{(\mathrm{R})}\left(x_{6}^{(\mathrm{R})}\right)^{\frac{\alpha}{\alpha-1}} \frac{\alpha}{1-\alpha}\left(x_{6}\right)^{\frac{2 \alpha-1}{1-\alpha}} d x_{6},
$$

where $x_{6} \ll 1$. When the above is substituted into (2.17) it allows for the integration from the retentate port molar fraction to the feed port molar fraction (so the integral is a positive number) over the membrane surface area as follows

$$
n^{(\mathrm{R})}\left(x_{6}^{(\mathrm{R})}\right)^{\frac{\alpha}{\alpha-1}} \frac{\alpha}{1-\alpha} \int_{x_{6}^{(R)}}^{x_{6}^{(F)}}\left(x_{6}\right)^{\frac{2 \alpha-1}{1-\alpha}} d x_{6}=\frac{\mathscr{P}_{\mathrm{SiH}_{4}}}{h} \Delta p \int_{0}^{A} d A .
$$

An expression for the molar flow rate on the retentate port is then obtained

$$
n^{(\mathrm{R})}\left[\left(\frac{x_{b}^{(R)}}{x_{b}^{(F)}}\right)^{\frac{\alpha}{\alpha-1}}-1\right]=\overline{\mathscr{P}}_{\mathrm{SiH}_{4}} A \Delta p,
$$

where $\overline{\mathscr{P}}_{\mathrm{SiH}_{4}}:=\frac{\mathscr{P}_{\mathrm{SiH}_{4}}}{h}$ is the permeance of $\mathrm{SiH}_{4}$ in the membrane, and $A$ is the area of the membrane. The ratio of molar fractions within square brackets can be expressed in terms of the stage cut,

$$
\theta:=\frac{n^{(\mathrm{P})}}{n^{(\mathrm{F})}},
$$

as follows. Compute the molar fraction of $\mathrm{SiH}_{4}$ in the permeate port

$$
x_{\mathrm{SiH}_{4}}^{(\mathrm{P})}=\frac{1}{\theta n^{(\mathrm{F})}} \int_{\text {retentate port }}^{\text {feed port }} y_{\mathrm{SiH}_{4}} d n .
$$

Using 2.18 and the dilute limit approximation $x_{\mathrm{SiH}_{4}}^{(\mathrm{P})} \approx 1$, and $y_{\mathrm{SiH}_{4}} \approx 1$ in 2.21 leads to the integral

$$
1=\frac{n^{(\mathrm{R})}}{\theta n^{(\mathrm{F})}}\left(x_{6}^{(\mathrm{R})}\right)^{\frac{\alpha}{\alpha-1}} \frac{\alpha}{1-\alpha} \int_{x_{6}^{(\mathrm{F})}}^{x_{6}^{(\mathrm{R})}}\left(x_{6}\right)^{\frac{2 \alpha-1}{1-\alpha}} d x_{6},
$$

which can be simplified by virtue of $n^{(\mathrm{F})}=n^{(\mathrm{R})}+n^{(\mathrm{P})}$ to

$$
\frac{\theta}{1-\theta}=\left(\frac{x_{6}^{(\mathrm{R})}}{x_{6}^{(\mathrm{F})}}\right)^{\frac{\alpha}{\alpha-1}}-1,
$$


the quantity on the left side is the retentate cut $n^{(\mathrm{P})} / n^{(\mathrm{R})}$. Here we define the stage impurity separation factor as

$$
\beta:=\frac{x_{6}^{(\mathrm{R})}}{x_{6}^{(\mathrm{F})}} ;
$$

this will prove to be a key parameter in the following analysis. Hence, $\beta>1$ for a slow permeant impurity, and $\beta<1$ for a fast permeant impurity ( $\beta>0$ always), and from 2.22

$$
\frac{\theta}{1-\theta}=\beta^{\frac{\alpha}{\alpha-1}}-1 \text {, }
$$

and

$$
\theta=1-\beta^{-\frac{\alpha}{\alpha-1}} .
$$

This is an important relationship since it relates molar flowrate ratio to mass fraction ratio. Say we want a stage impurity separation factor of $\beta=50$ (slow permeant), then the stage cut needed is $\theta=1-50^{-\frac{\alpha}{\alpha-1}}$. If the average effective separation factor is relatively low, say $\alpha=1.5$, then $\theta=1-\frac{1}{50^{3}}$, that is, very high stage cuts are needed $\theta \approx 1$. As we will see later, the higher the stage cut, the longer is the separation time.

Substitution of (2.22) and (2.24) into (2.19) produces the desired result

$$
n^{(\mathrm{R})}=\frac{\overline{\mathscr{P}}_{\mathrm{SiH}_{4}} A \Delta p}{\beta^{\frac{\alpha}{\alpha-1}}-1},
$$

That is, in a dilute binary mixture, the retentate molar flowrate is directly proportional to the trans-membrane pressure difference and the area of the membrane. It is inversely proportional to a term that depends on the stage impurity separation factor, $\beta$, and the average, effective separation factor of the mixture, $\alpha$, relative to the major species; the latter is a function of the trans-membrane pressure ratio. Therefore both pressure difference and pressure ratio affect the retentate molar flowrate.

Alternatively, the expression can be written in terms of the stage cut,

$$
n^{(\mathrm{R})}=\frac{1-\theta}{\theta} \overline{\mathscr{P}}_{\mathrm{SiH}_{4}} A \Delta p \text {, }
$$

where the permeability of the impurity is still involved in the formula but not apparent. An appealing aspect of (2.27) is that if the stage cut is fairly constant, and the membrane area and thickness known, the constant of proportionality between the measured rententate molar flowrate, $n^{(\mathrm{R})}$, and the trans-membrane pressure drop delivers a measure of the permeability of silane, $\mathscr{P}_{\mathrm{SiH}_{4}}=\overline{\mathscr{P}}_{\mathrm{SiH}_{4}} \times h$, without measuring the permeate molar flowrate, and only measuring the feed molar flowrate as we see 
next in (2.28). This is a useful observation that simplifies experimental work since the permeate is a silane-rich, pyrophoric stream.

The feed and permeate molar flowrates can be determined from the retentate (2.26), assuming no accumulation of mass in the membrane module $\left(n^{(\mathrm{F})}=n^{(\mathrm{P})}+\right.$ $\left.n^{(\mathrm{R})}\right)$, thus

$$
\begin{aligned}
& n^{(\mathrm{F})}=\frac{1}{1-\theta} n^{(\mathrm{R})}, \quad \text { and }, \\
& n^{(\mathrm{P})}=\frac{\theta}{1-\theta} n^{(\mathrm{R})}=\left(\beta^{\frac{\alpha}{\alpha-1}}-1\right) n^{(\mathrm{R})} .
\end{aligned}
$$

Another ratio of practical interest is the one involving the impurity mass fraction in the permeate, namely

$$
\delta:=\frac{x_{6}^{(\mathrm{P})}}{x_{6}^{(\mathrm{F})}},
$$

which can be shown to be a function of $\beta$ on the basis of the same mass balance argument used in (2.28) and (2.29), that is

$$
\delta:=\frac{\beta^{\frac{\alpha}{\alpha-1}}-\beta}{\beta^{\frac{\alpha}{\alpha-1}}-1} .
$$

Since $0 \leqslant \delta \leqslant 1$, say for a slow permeant impurity, then $\beta \geqslant 1$, which shows that the impurity mass fraction in the retentate is higher than the feed. Another route to demonstrate the correctness of (2.31) is computing directly the mass fraction of the impurity in the permeate, that is

$$
x_{6}^{(\mathrm{P})}=\frac{1}{\theta n^{(\mathrm{F})}} \int_{\text {retentate port }}^{\text {feed port }} y_{6} d n,
$$

using (2.8) and (2.18); demonstrated in the Supporting Information section. The foregoing demonstrates that the stage impurity separation factor, $\beta$, determines many of the features of the separation process, and the purpose of the following sections is to relate this parameter with other operation quantities for particular flow loops. In addition, it is demonstrated that the permeability constant is not directly used in any of the results, instead, only the binary ratio of permeability coefficients and the permeance of the main species $\mathrm{SiH}_{4}$ are the necessary permeability-related data required. 


\subsection{Slow-permeant impurity depletion (permeate recircula- tion)}

Slower permeates than silane in PDMS (top of table 3.1) follow the retentate stream. Likewise, heavy impurities in CA (not shown in table 3.2.). An enhanced separation of slower permeates can be obtained by recycling the permeate into a feed tank which is rich in silane (fig. 2.3). The intent in building this loop is to keep the high-value material in the original tank and transfer to a storage tank a small enough amount of gas with higher content of impurity than the purified mixture left in the tank. Under certain operating conditions, it may be possible to reduce the concentration of impurities in the feed tank to the needed specifications (table 1.1). This will depend on:

- the initial concentration of the impurity,

- the desired final concentration,

- the amount of material transferred,

- the time to complete the transfer,

- the membrane area and thickness,

- the pressure on either side of the membrane, and

- the permeability coefficient of the silane and impurity.

A number of important auxiliary devices (valves, pressure regulators, tubing heater, etc.) are needed for the practical operation of the loop (fig. 2.3); these are not discussed in this article.

The return of the permeate back to the feed tank (fig. 2.3 dotted semi-circle line) allows for multiple recirculations of the feed stream. A recirculation factor can be defined from 2.28$)$ and $(2.29)$ as

$$
\gamma:=\frac{1}{2}\left(\frac{n^{(\mathrm{P})}}{n^{(\mathrm{R})}}+\frac{n^{(\mathrm{F})}}{n^{(\mathrm{R})}}\right)=\frac{1+\theta}{2(1-\theta)},
$$

and obviously, it can be quite high for large stage cut values, $\theta \approx 1$.

The decreasing concentration of the impurity in the tank can be obtained by a simple mass balance assuming that the volume of the membrane module is much smaller than the feed tank. The process purification factor of interest is defined as

$$
\Gamma:=\frac{x_{6}^{(\mathrm{T})}\left(t_{0}\right)}{x_{b}^{(\mathrm{T})}\left(t_{f}\right)},
$$




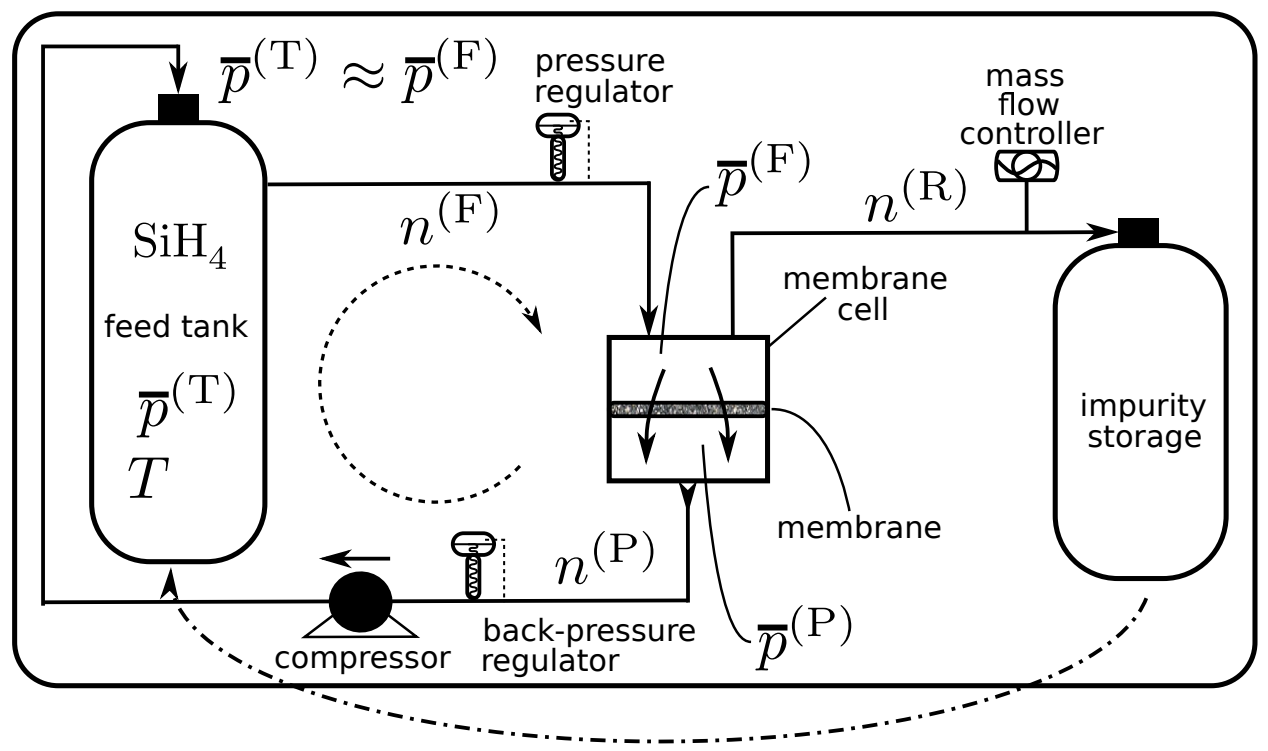

Fig. 2.3: Slow-permeant impurity depletion loop. The silane product is concentrated in the original feed tank via recirculation of the permeate (dashed semi-circle line). An impurity-rich, slow rententate flow is transferred into storage. The impurity can be recycled as feed (dashed-dotted line).

that is, the ratio of the initial molar fraction of the impurity in the tank (superscript $\mathrm{T})$ to the final molar fraction at the end of the operation at time $t_{f}$. The balance of total number of moles in the system, ignoring the membrane cell volume and tubing, is

$$
\mathrm{d}_{t} M^{(\mathrm{T})}=-n^{(\mathrm{R})}(t),
$$

where $M^{(\mathrm{T})}$ is the total number of moles in the tank. Using the above, the impurity mole balance is

$$
\mathrm{d}_{t}\left(M^{(\mathrm{T})} x_{6}^{(\mathrm{T})}(t)\right)=-x_{6}^{(\mathrm{R})} n^{(\mathrm{R})}(t)=x_{6}^{(\mathrm{R})} \mathrm{d}_{t} M^{(\mathrm{T})},
$$

which simplifies to

$$
\frac{d M^{(\mathrm{T})}}{M^{(\mathrm{T})}}=\frac{d x_{6}^{(\mathrm{T})}}{x_{6}^{(R)}-x_{6}^{(T)}}
$$

Assuming the feed composition is the same as the tank composition, $x_{6}^{(\mathrm{F})} \equiv x_{6}^{(\mathrm{T})}$. Note the permeate composition is different than the tank composition since the tank has the majority of the impurity, and every effort needs to be made to avoid backmixing 
across the compressor. Using (2.23) in the previous equation, we can integrate

$$
\frac{d M^{(\mathrm{T})}}{M^{(\mathrm{T})}}=\frac{d x_{b}^{(\mathrm{T})}}{(\beta-1) x_{6}^{(T)}}
$$

between times $t_{0}$ and $t_{f}$ from $M_{0}^{(\mathrm{T})}$ to $M_{f}^{(\mathrm{T})}$, and from $x_{b}^{(\mathrm{T})}\left(t_{0}\right)$ and $x_{b}^{(\mathrm{T})}\left(t_{f}\right)$ to obtain

$$
\Gamma=\left(\frac{M^{(\mathrm{T})}\left(t_{0}\right)}{M^{(\mathrm{T})}\left(t_{f}\right)}\right)^{\beta-1},
$$

where the ratio $\frac{M^{(\mathrm{T})}\left(t_{0}\right)}{M^{(\mathrm{T})}\left(t_{f}\right)}$ of the total number of moles at the initial time in the tank to the final total number of moles in the tank is controlled by how much material withdrawal can be tolerated in the process. Say this withdrawal is denoted by $\lambda$ where $0<\lambda<1$, then $M^{(\mathrm{T})}\left(t_{0}\right) / M^{(\mathrm{T})}\left(t_{f}\right)=1 /(1-\lambda)$ and $(2.36)$ gives

$$
\beta=\frac{\ln \left((1-\lambda) \Gamma^{-1}\right)}{\ln (1-\lambda)},
$$

relating the stage impurity separation factor to the process purification factor (again, note $\beta>1$ for a fast-permeant impurity). The latter is specified by the purification goal (impurity tolerance in the final product) and the initial impurity concentration which should be small in view of the dilute assumption in this analysis. Note that once the purification process is executed, the impurity molar fraction in the storage tank is of critical importance for recycling in future runs. It can be calculated from the mass quantities in the tank and mass withdrawn from the tank, namely

$$
m^{(\mathrm{T})}(t)=M^{(\mathrm{T})}(t)\left(M_{\mathrm{SiH}_{4}} x_{\mathrm{SiH}_{4}}^{(\mathrm{T})}(t)+M_{6} x_{6}^{(\mathrm{T})}(t)\right)
$$

and

$$
m^{(\mathrm{S})}\left(t_{f}\right)=m^{(\mathrm{T})}\left(t_{0}\right)-m^{(\mathrm{T})}\left(t_{f}\right)
$$

respectively. Here $M_{\mathrm{SiH}_{4}}$ and $M_{6}$ are the molar masses of the species involved, and the initial total number of moles in the tank is approximately $M^{(\mathrm{T})}\left(t_{0}\right)=\frac{p^{(F)} V}{R T_{0}}$. From (2.38) and 2.39) any species mass in the storage tank is given by

$$
m_{6}^{(\mathrm{S})}\left(t_{f}\right)=M^{(\mathrm{T})}\left(t_{0}\right) M_{6}\left(x_{6}^{(\mathrm{T})}\left(t_{0}\right)-(1-\lambda) x_{6}^{(\mathrm{T})}\left(t_{f}\right)\right),
$$

and the corresponding number of moles follows from

$$
M_{b}^{(\mathrm{S})}\left(t_{f}\right)=\frac{m_{6}^{(\mathrm{S})}\left(t_{f}\right)}{M_{6}},
$$

Oak Ridge National Laboratory Report ORNL/TM-2016/278 pp. 1-41 
which provides the mole fraction of the impurity in the storage tank at the end of the process time $t_{f}$

$$
x_{6}^{(\mathrm{S})}\left(t_{f}\right)=\frac{M_{b}^{(\mathrm{S})}\left(t_{f}\right)}{M_{6}^{(\mathrm{S})}\left(t_{f}\right)+M_{\mathrm{SiH}_{4}}^{(\mathrm{S})}\left(t_{f}\right)},
$$

recall $x_{\mathrm{SiH}_{4}}^{(\mathrm{S})}\left(t_{f}\right)=1-x_{6}^{(\mathrm{S})}\left(t_{f}\right)$. If the final concentration of the impurity in the storage tank, 2.42), is still considered dilute, and sufficient accumulation of material has taken place from multiple runs, it is often possible to re-use the retentate as feed material and improve the material recovery of the process.

Knowledge of $\beta$, through (2.37), and the specification of other necessary quantities, allows for computing the retentate molar flowrate using (2.26). It remains to compute the process time, $t_{f}-t_{0}$, needed for a particular purification operation. To that end, we first assume that $\Delta p$ and $p_{\mathrm{R}}$ are constants, that is, the compressor is able to keep the required pressure drop and pressure ratio fairly constant throughout the operation. Therefore the total time $t_{f}$ of the operation needed to achieve the separation desired can be computed as follows. If the constant tank volume is $V$ at initial temperature $T\left(t_{0}\right)$, then from (2.34), 2.27), and the ideal gas equation of state assumption for the feed tank,

$$
\bar{p}^{(\mathrm{T})} V^{(T)} \mathrm{d}_{t}\left(\frac{1}{M^{(\mathrm{T})}}\right)=R \mathrm{~d}_{t} T^{(\mathrm{T})},
$$

one obtains, after time integration, the estimated operation final time starting from $t_{0}=0$

$$
\left.t_{f}\right|_{p}=\frac{p^{(F)}}{\Delta p} \frac{V}{R T_{0}} \frac{\theta}{1-\theta} \frac{\lambda}{\overline{\mathscr{P}}_{\mathrm{SiH}_{4} A} A} \text {, }
$$

assuming that the volume of the membrane cell and tubing is negligible compared to the tank volume. Note that in the case of constant pressure operation, the molar flow rate $n^{(\mathrm{R})}$ is a constant, also in the previous formula $p^{(\mathrm{F})} \approx p^{(\mathrm{T})}$. In a real application of this process, the retentate molar flow rate is typically small, which makes operation times long. To mitigate this problem, a lower pressure $p^{(\mathrm{F})}$ could be used but the gains are small since the $\Delta p$ is also reduced unless a near vacuum condition is created in the permeate side of the membrane. Another way to look at this is that pressure is not the primary means to speed up the separation process. In fact by reasons of safety concerns in handling silane, the lower the pressure is (near atmospheric), the better, as long as the time for carry out the separation is attractive. This will be discussed in the Results section.

A potentially unwanted effect of constant pressure operation is the need to increase the temperature in the tank and membrane cell to keep pressure constant while decreasing the gas mass. The relative absolute temperature variation in the tank can 
be shown to be

$$
\frac{\Delta T}{T\left(t_{0}\right)}=\frac{\lambda}{1-\lambda}
$$

where $\Delta T:=T\left(t_{f}\right)-T\left(t_{0}\right)$. This is a relatively fast increasing temperature variation with increasing $\lambda$. If say $\lambda \approx 0.1$ the increase in temperature is about $33^{\circ} \mathrm{C}$ above ambient temperature. In cases where a large transfer of material is desired (see multi-cycles in section 3), the increase in temperature is substantial and it limits the maximum material transfer in view of the maximum operating temperature of the membrane material.

An isothermal operation can be employed as an alternative to constant pressure; here pressure will decay with time requiring attention to maintaining a sufficient driving force for separation. Using (2.34), (2.27), and the ideal gas equation of state for the feed tank in the form

$$
V^{(T)} \mathrm{d}_{t} \bar{p}^{(\mathrm{T})}=R T^{(\mathrm{T})} \mathrm{d}_{t} M^{(\mathrm{T})}
$$

the time integration gives

$$
\Delta p(t)=\Delta p\left(t_{0}\right) \exp \left(-\frac{R T}{V} \frac{(1-\theta)}{\theta} \overline{\mathscr{P}}_{\mathrm{SiH}_{4}} A\left(t-t_{0}\right)\right)
$$

that is, an exponential decay of the trans-membrane pressure drop with time. This result assumes that the permeate pressure, $\bar{p}^{(\mathrm{P})}$, is fairly constant; in practice we would like to have it as low as possible to vacuum. Using the exponential pressure variation with time in (2.34) and (2.27), the operation final time can be computed as

$$
\left.t_{f}\right|_{T}=\ln \left(\frac{1}{1-\lambda}\right) \frac{V}{R T} \frac{\theta}{1-\theta} \frac{1}{\overline{\mathscr{P}}_{\mathrm{SiH}_{4}} A},
$$

where $t_{0}=0$. The above assumes that the compressor is able to keep the low pressure relatively constant while the pressure in the tank is reduced to keep the temperature constant. This arrangement may call for a vacuum pump in tandem with a compressor to take advantage of imposing a low pressure in the permeate cell chamber in systems with low effective separation factors (see cases in section 3). The operation time at constant temperature is greater than its counterpart at constant pressure since using 2.43) and 2.46), the ratio

$$
\frac{\left.t_{f}\right|_{T}}{\left.t_{f}\right|_{P}}=\frac{1-p_{\mathrm{R}}}{\lambda} \ln \left(\frac{1}{1-\lambda}\right)
$$

is always greater than one. Typical values for $p_{\mathrm{R}}$ and $\lambda\left(e . g \cdot p_{\mathrm{R}}=0.01\right.$ and $\left.\lambda=0.05\right)$, suggest a small increase in processing time (about $2 \%$ ). Large values of transfer for 
$\lambda$ suggest an increase in processing time by as much as a factor of three. Therefore according to 2.46), when a constant temperature is used, it is advantageous to use the highest possible temperature the system can withstand in order to reduce the operation time. The factors affecting the operation time can be quickly grasped from (2.46). Large membrane area, large permeance of silane, small stage cut, small feed tank volume, and small material transfer help reduce the operation time. These are however conflicting requirements. As it has seen before, the stage cut is largely dictated by the membrane permeability, the initial level of impurity, and the final purification level desired. The typical stage cut is often large which increases the operation time.

A final comment on the operation of the slow-permeant impurity loop is that it can be also used with a fast-permeant impurity by allowing a large transfer, say $\lambda \approx 0.95$, to the impurity tank, thereby leaving the majority of the impurity in the feed tank at the final time, and transferring the product to the impurity tank. The chief disadvantage of this operation is that for cases of small effective separation factor of silane relative to the impurity, the entire gas transfer from the feed tank to the impurity tank can take a very long time to achieve the purification needed, and at this point it is more efficient to consider a more elaborated loop aimed at the fastpermeant impurity depletion; as described next. Another practical impediment for this approach is the prohibitively high temperature or low pressure in the feed tank resulting from the large mass withdrawal.

\subsection{Fast-permeant impurity depletion (retentate recircula- tion)}

Faster permeants than silane in PDMS (bottom of table 3.1) follow the permeate stream, therefore virtually no separation will take place in a loop as analyzed earlier (section 2.2). A fast-permeant impurity depletion loop (fig. 2.4) recirculates the retentate (larger loop), and a portion of the permeate (smaller loop). The idea here is similar to the slow-permeant impurity loop, where a relatively small quantity of permeate is withdrawn after a high recirculation rate of the retentate. This avoids a large amount of material transfer from the feed tank to the impurity storage tank if we were to use the previously discussed loop (sec. 2.2).

As done earlier, assuming no mass accumulation in the membrane cell and on the compressor, the mass balances

$$
\begin{aligned}
n^{(\mathrm{F})} & =n^{(\mathrm{R})}+n^{(\mathrm{P})}, \text { and } \\
n^{(\mathrm{T})}+n^{(\mathrm{P})} & =n^{(\mathrm{F})}+n^{(\mathrm{S})}
\end{aligned}
$$


lead to

$$
n^{(\mathrm{T})}=n^{(\mathrm{S})}+n^{(\mathrm{R})}
$$

Defining the process cut

$$
\Theta=\frac{n^{(\mathrm{S})}}{n^{(\mathrm{R})}},
$$

where $\Theta>0$ and the upper bound is to be found later, we can define recirculation factors as follows. The larger loop recirculation factor can be defined as

$$
\gamma_{1}:=\frac{n^{(\mathrm{R})}+n^{(\mathrm{F})}+n^{(\mathrm{T})}+\left(n^{(\mathrm{P})}+n^{(\mathrm{T})}\right)}{4 n^{(\mathrm{S})}},
$$

then using (2.28), 2.29), and (2.48) we get

$$
\gamma_{1}=\frac{3+2 \Theta+\frac{1+\theta}{1-\theta}}{4 \Theta}
$$

Similarly for the smaller loop, the recirculation factor is defined as

$$
\gamma_{2}:=\frac{\left(n^{(\mathrm{P})}+n^{(\mathrm{T})}\right)+n^{(\mathrm{F})}+n^{(\mathrm{P})}}{3 n^{(\mathrm{S})}},
$$

hence

$$
\gamma_{2}=\frac{1+\Theta+\frac{1+2 \theta}{1-\theta}}{3 \Theta} .
$$

As it was done before in $(2.34$, the balance of total number of moles in the system (fig. 2.4) is

$$
\mathrm{d}_{t} M^{(\mathrm{T})}=n^{(\mathrm{R})}-n^{(\mathrm{T})}=-n^{(\mathrm{S})}(t)
$$

The corresponding impurity mole balance is

$$
\mathrm{d}_{t}\left(M^{(\mathrm{T})} x_{a}^{(\mathrm{T})}(t)\right)=-x_{a}^{(\mathrm{S})} n^{(\mathrm{S})}(t)=x_{a}^{(\mathrm{S})} \mathrm{d}_{t} M^{(\mathrm{T})},
$$

which simplifies to

$$
\frac{d M^{(\mathrm{T})}}{M^{(\mathrm{T})}}=\frac{d x_{a}^{(\mathrm{T})}}{\beta^{-1} x_{a}^{(R)}-x_{a}^{(T)}},
$$

when using 2.23 and assuming $x_{a}^{(\mathrm{S})} \equiv x_{a}^{(\mathrm{F})}$. A comment on 2.23 for the present case of a fast-permeant impurity is in order. Note that in this case, $0<\beta<1$, and ideally $\beta=0$ produces the maximum separation; to be seen later, this maximum does not set the optimum value for the separation cut $\Theta$ that renders the separation the shortest processing time.

Oak Ridge National Laboratory Report ORNL/TM-2016/278 pp. 1-41 


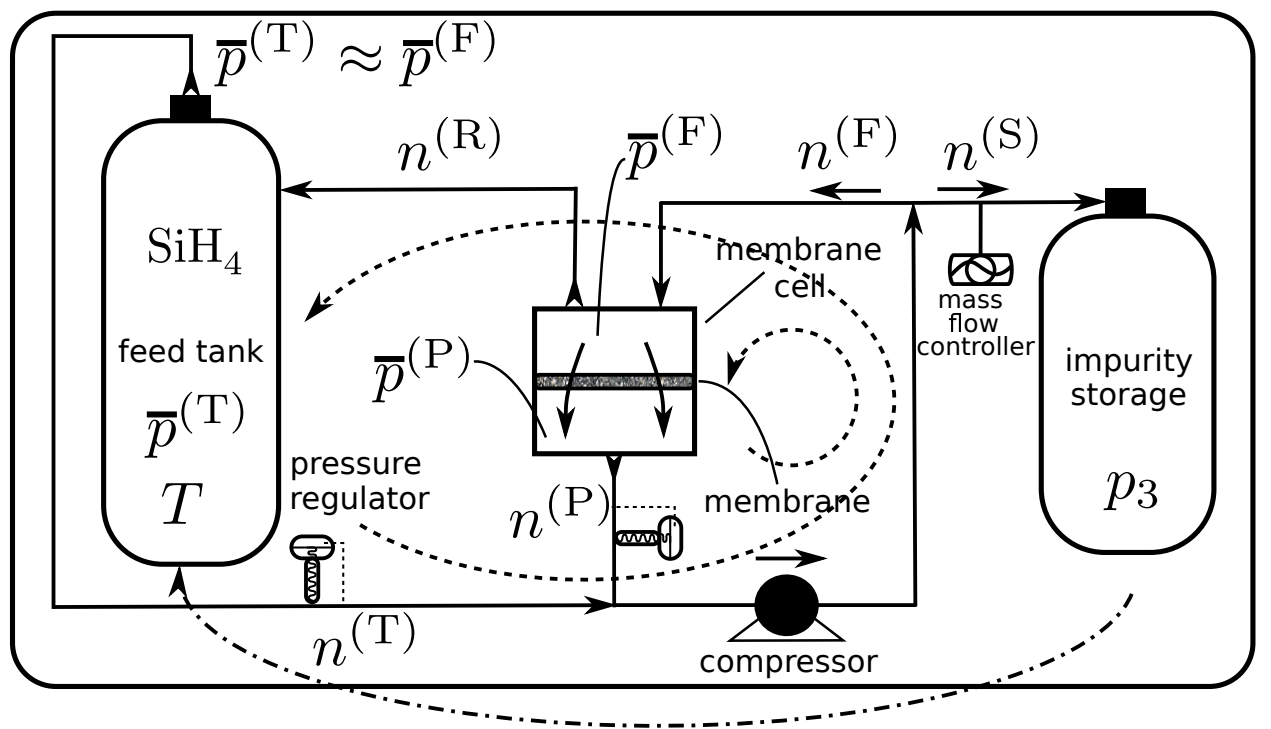

Fig. 2.4: Fast-permeant impurity depletion loop. The silane product is concentrated in the feed tank via recirculation of the retentate, and the impurity is concentrated on the smaller loop which discharges to the impurity storage. The impurity can be recycled as a feed (dashed-dotted line).

The job at hand now is to relate $x_{a}^{(\mathrm{R})}$ to $x_{a}^{(\mathrm{T})}$ in order to make further progress in (2.52). For this purpose, we use 2.47), 2.23), and again assuming $x_{\mathfrak{a}}^{(\mathrm{S})} \equiv x_{\mathfrak{a}}^{(\mathrm{F})}$ we obtain

$$
x_{a}^{(\mathrm{T})} n^{(\mathrm{T})}+x_{a}^{(\mathrm{P})} n^{(\mathrm{P})}=x_{a}^{(\mathrm{F})} n^{(\mathrm{F})}+x_{a}^{(\mathrm{S})} n^{(\mathrm{S})}
$$

or

$$
x_{a}^{(\mathrm{T})} n^{(\mathrm{T})}+x_{a}^{(\mathrm{P})} n^{(\mathrm{P})}=\beta^{-1} x^{(\mathrm{R})}\left(n_{a}^{(\mathrm{F})}+n_{a}^{(\mathrm{S})}\right) .
$$

The molar flux of the impurity into the permeate side of the membrane can be computed directly from

$$
x_{a}^{(\mathrm{P})} n^{(P)}=\int_{\text {retentate port }}^{\text {feed port }} y_{a} d n,
$$

using (2.9), 2.7), and (2.18) one obtains

$$
x_{a}^{(\mathrm{P})} n^{(P)}=x_{a}^{(\mathrm{R})} n^{(R)}\left(\beta^{-\frac{\alpha^{\prime}}{\alpha^{\prime}-1}}-1\right),
$$

where we defined

$$
\alpha^{\prime}:=\bar{\alpha}_{a, \mathrm{SiH}_{4}}=\alpha^{-1}
$$

Oak Ridge National Laboratory Report ORNL/TM-2016/278 pp. 1-41 
which is greater than unit for a fast-permeant impurity (recall the use of 2.7) to compute $\alpha^{\prime}$ ). Returning to (2.53) and substituting (2.54), (2.28), and (2.48), we arrive (after some algebra) to the desired relationship

$$
\beta^{-1} x_{a}^{(R)}=\frac{1+\Theta}{\beta+\Theta} x_{a}^{(T)},
$$

which does not involve $\alpha^{\prime}$; this relationship is the extension of the much simpler case needed in (2.35). Direct use into the tank mass balance differential equation (2.52) results in

$$
\frac{d M^{(\mathrm{T})}}{M^{(\mathrm{T})}}=\frac{d x_{a}^{(\mathrm{T})}}{\frac{1-\beta}{\Theta+\beta} x_{a}^{(T)}},
$$

which is the counterpart of $(2.35)$, with solution

$$
\Gamma=\left(\frac{M^{(\mathrm{T})}\left(t_{0}\right)}{M^{(\mathrm{T})}\left(t_{f}\right)}\right)^{\frac{1-\beta}{\Theta+\beta}},
$$

which provides a central result for the stage impurity separation factor using $M^{(\mathrm{T})}\left(t_{0}\right) / M^{(\mathrm{T})}\left(t_{f}\right)=$ $1 /(1-\lambda)$

$$
\beta=\frac{\ln \left((1-\lambda) \Gamma^{\Theta}\right)}{\ln \left((1-\lambda) \Gamma^{-1}\right)},
$$

specific for the fast-permeant impurity depletion loop; this is the counterpart of (2.37). Note that by taking the reciprocal of (2.57) and setting $\Theta=0$ one obtains (2.37). Since a fast-permeant impurity calls for $0<\beta<1$, the process cut is bounded by

$$
0<\Theta \leqslant \frac{\ln (1-\lambda)}{\ln \left(\Gamma^{-1}\right)} .
$$

Typically, $\Gamma$ and $\lambda$ are given input data, thus (2.58) delivers a bound on $\Theta$, which determines $\beta$ through (2.57). The maximum value

$$
\Theta_{\max }=\frac{\ln (1-\lambda)}{\ln \left(\Gamma^{-1}\right)},
$$

makes $\beta=0$ which is an optimum separation but does not minimize the the processing time (as we will cover in the following paragraph). As was previously evinced (sec. 2.2), all other quantities of interest follow from $\beta$, including the operation times. In the same way we used (2.34) to arrive to $(2.43)$ and (2.46), we use (2.51), (2.48) 
and (2.27) to calculate the processing time at constant tank pressure (variable, timedependent temperature)

$$
\left.t_{f}\right|_{p}=\frac{p^{(F)}}{\Delta p} \frac{V}{R T_{0}} \frac{\theta}{1-\theta} \frac{\lambda}{\Theta \overline{\mathscr{P}}_{\mathrm{SiH}_{4} A} A},
$$

which differs from 2.43 by a $\Theta^{-1}$ factor, and at constant tank temperature (variable, time-dependent pressure) we obtain

$$
\left.t_{f}\right|_{T}=\ln \left(\frac{1}{1-\lambda}\right) \frac{V}{R T} \frac{\theta}{1-\theta} \frac{1}{\Theta \mathscr{P}_{\mathrm{SiH}_{4}} A} ;
$$

here again, this differs from (2.46) by a $\Theta^{-1}$ factor. It is clear from 2.60) and (2.61) that the fast-permeant impurity depletion loop is a slower operation than the the slowpermeant impurity depletion loop (compare against (2.43) and (2.46) respectively). The slowdown factor is $\Theta^{-1}$, if everything else remains the same. A quick example helps to firm ideas. If the material recovery wanted is high, say $95 \%$, thus $\lambda=0.05$, and if the purification factor needed is $\Gamma=1152$ then $\Theta_{\max }^{-1}=137$, that is, a two orders of magnitude slower process.

The minimum operation time occurs when the factor $\frac{\theta}{1-\theta} \frac{1}{\Theta}$ in 2.60) and 2.61) is a minimum with respect to $\Theta$. The optimum, $\Theta^{*}$, of the factor solves

$$
\frac{\Theta^{*}}{\beta^{*}\left(1-\beta^{*} \frac{1}{\alpha^{\prime}-1}\right)}=\left(\alpha^{\prime}-1\right)\left(1-\frac{\ln (1-\lambda)}{\ln \Gamma}\right)
$$

and it is not available in direct analytical form, therefore we compute the value numerically (using a non-linear solver) and present results later in tabular form. The initial value for the numerical solution is critical for the convergence of the non-linear solver, we compute a range of $\left.t_{f}\right|_{T}$ values from (2.61) in the interval (2.58) and use the approximate minimum as an initial guess. by

Likewise (2.38) and (2.39), the mass in the impurity storage tank is determined

$$
m^{(\mathrm{S})}\left(t_{f}\right)=m^{(\mathrm{T})}\left(t_{0}\right)-m^{(\mathrm{T})}\left(t_{f}\right) .
$$

As explained earlier, this mass can be accumulated between new runs and given enough material, it can be recycled as feed. The impurity mole fraction in the recycled material is given by 2.42 .

Finally for completeness and clarity we list the modified version of some formulae for the present loop case used in (2.60) and (2.61). From (2.25) and (2.55)

$$
\theta=1-\beta^{\frac{1}{\alpha^{\prime}-1}} \text {, }
$$

Oak Ridge National Laboratory Report ORNL/TM-2016/278 pp. 1-41 
and from 2.31

$$
\delta=\frac{\beta^{-\frac{1}{\alpha^{\prime}-1}}-\beta}{\beta^{-\frac{1}{\alpha^{\prime}-1}}-1},
$$

where here $\beta$ is as in (2.57). The optimum equation in 2.62) is obtained using (2.63) and (2.57) in the differentiation of the factor $\frac{\theta}{1-\theta} \frac{1}{\Theta}$ with respect to $\Theta$. Finally, the present depletion loop can be also used with a slow-permeant impurity by performing large transfers, say $\lambda \approx 0.95$. The drawabacks of this approach are similar to what was mentioned alread for the slow-permeant impurity depletion loop, namely, large transfer times, high temperature or low trans-membrane pressure drop. The use of a slow-permeant impurity depletion loop for a slow-permeant impurity is the recommended approach.

\section{Results}

In this section we present calculations using the analytic expressions derived previously (sec. 2). We make plausible assumptions for a silane crude composition based on our laboratory experience and estimate parameters needed to execute a purification process aimed at delivering an electronics-grade (or better) silane product (table 1.1).

As mentioned before, there is a need for reliable permeability data for silane and its impurities. We use scarce data found in the open publication domain for the purpose of this study. Permeability data for a PDMS membrane material (table 3.1) was used for some of the results presented. This material was tested in liquid dichlorosilane for one year and proved to be fairly stable according to VOROTYNTSEV et al. (2013). This is an assuring fact but for our application we could accommodate a less stable membrane material by simply exchanging membranes periodically; as often as in each purification run. We also make predictions for a cellulose acetate (CA) membrane material based on limited permeability data (HSIEH AND KELLER II, 1992) for separation of hydrogen and silane (table 3.2). Comparison with additional data involving hydrogen for this material (PAULY, 1999) led us to speculate about the utility of this material to remove other impurities difficult to process with PDMS. Therefore, we propose a dual approach to remove impurities by combining a solubility selectivity method (PDMS) with a mobility selectivity (CA) separation. Both materials have been investigated regarding stability in the presence of silane and considered satisfactory (HSIEH AND KELLER II, 1992; VOROTYNTSEV et al., 2013).

Before continuing we provide some comments on the data used. The data for PDMS (table 3.1) is assumed to be at room temperature since this is not explicitly reported by VOROTYNTSEV et al. (2013). We show on the rightmost column the error of the selectivity factor relative to methane compared to corresponding selectivity

Oak Ridge National Laboratory Report ORNL/TM-2016/278 pp. 1-41 
Table 3.1: Pure-component, a, permeability constant, $\mathscr{P}_{a}$, (assumed at ambient temperature) of silane and impurities in a PDMS membrane (VOROTYNTSEV et al., 2008); units of $\mathrm{mol} \mathrm{m} \mathrm{m} \mathrm{m}^{-2} \mathrm{~Pa}^{-1} \mathrm{~s}^{-1} \times 10^{13}$. Slower permeants listed on the top table; faster permeants, on the bottom table. The permeability ratio $\alpha_{a, b}^{*}:=\frac{\mathscr{P}_{a}}{\mathscr{P}_{b}}$ is called the ideal selectivity factor or ideal separation factor. $\epsilon_{(\cdot, \cdot)}$ is the separation factor error relative to data presented by PAULY (1999).

\begin{tabular}{|c|c|c|c|c|}
\hline 6th-Gas & $\mathscr{P}_{6}$ & $\alpha_{\mathrm{SiH}_{4}, 6}^{*}$ & $\alpha_{\mathrm{CH}_{4}, 6}^{*}$ & $\epsilon_{\mathrm{CH}_{4}, 6}[\%]^{\ddagger}$ \\
\hline $\mathrm{N}_{2}$ & 0.44 & 3.40 & 2.73 & -3.9 \\
\hline $\mathrm{CO}$ & 0.48 & 3.13 & 2.5 & - \\
\hline $\mathrm{He}$ & 0.53 & 2.83 & 2.26 & -5.4 \\
\hline $\mathrm{O}_{2}$ & 0.86 & 1.74 & 1.4 & -2.8 \\
\hline $\mathrm{Ar}$ & 0.93 & 1.61 & 1.29 & - \\
\hline $\mathrm{H}_{2}$ & 1.00 & 1.50 & 1.25 & -12.0 \\
\hline $\mathrm{CH}_{4}$ & 1.20 & 1.25 & 1.0 & - \\
\hline Gas & $\mathscr{P}_{\mathrm{SiH}_{4}}$ & $\alpha_{\mathrm{SiH}_{4}, \mathrm{SiH}_{4}}^{*}$ & $\alpha_{\mathrm{SiH}_{4}, \mathrm{CH}_{4}}^{*}$ & $\epsilon_{\mathrm{CH}_{4}, 6}[\%]^{\ddagger}$ \\
\hline $\mathrm{SiH}_{4}$ & 1.5 & 1.0 & 1.25 & - \\
\hline ath-Gas & $\mathscr{P}_{a}$ & $\alpha_{a, \mathrm{SiH}_{4}}^{*}$ & $\alpha_{a, \mathrm{CH}_{4}}^{*}$ & $\epsilon_{a, \mathrm{CH}_{4}}[\%]^{\ddagger}$ \\
\hline $\mathrm{C}_{2} \mathrm{H}_{6}$ & 2.7 & 1.80 & 2.25 & -28.3 \\
\hline $\mathrm{B}_{2} \mathrm{H}_{6}$ & 2.7 & 1.80 & 2.25 & - \\
\hline $\mathrm{C}_{2} \mathrm{H}_{4}$ & 3.7 & 2.47 & 3.08 & +12.8 \\
\hline $\mathrm{CO}_{2}$ & 4.7 & 3.10 & 3.92 & +12.6 \\
\hline $\mathrm{PH}_{3}$ & 5.8 & 3.87 & 4.83 & - \\
\hline $\mathrm{C}_{3} \mathrm{H}_{8}$ & 8.2 & 5.47 & 6.83 & - \\
\hline $\mathrm{AsH}_{3}$ & 8.3 & 5.53 & 6.92 & - \\
\hline $\mathrm{C}_{3} \mathrm{H}_{6}$ & 10.5 & 7.00 & 8.75 & - \\
\hline $\mathrm{H}_{2} \mathrm{O}$ & 26.5 & 17.67 & 22.1 & - \\
\hline $\mathrm{n}-\mathrm{C}_{4} \mathrm{H}_{10}$ & $30.1^{\dagger}$ & 20.07 & 25.1 & - \\
\hline $\mathrm{n}-\mathrm{C}_{5} \mathrm{H}_{12}$ & $67.0^{\dagger}$ & 44.67 & 55.8 & - \\
\hline $\mathrm{SiCl}_{4}$ & 30.0 & 20.00 & 25.0 & - \\
\hline $\mathrm{SiH}_{2} \mathrm{Cl}_{2}$ & 45.0 & 30.00 & 37.5 & - \\
\hline $\mathrm{SiHCl}_{3}$ & 60.0 & 40.00 & 50.0 & - \\
\hline
\end{tabular}

${ }^{\dagger}$ From BASU et al. (2010).

₹From PAULY (1999).

Oak Ridge National Laboratory Report ORNL/TM-2016/278 pp. 1-41 
Table 3.2: Pure-component, a, permeance, $\overline{\mathscr{P}}_{a},\left(28^{\circ} \mathrm{C}-37^{\circ} \mathrm{C}\right)$ of silane and impurities in a CA membrane (HSIEH AND KELLER II, 1992); units of $\mathrm{mol} \mathrm{m}^{-2} \mathrm{~Pa}^{-1} \mathrm{~s}^{-1} \times$ $10^{11}$. Faster permeants listed on the bottom table. The permeability ratio $\alpha_{a, b}^{*}:=\frac{\mathscr{P}_{a}}{\mathscr{P}_{b}}$ is called the ideal selectivity factor or ideal separation factor.

\begin{tabular}{|c|c|c|c|c|c|}
\hline Gas & \multicolumn{5}{|c|}{$\overline{\mathscr{P}}_{\mathrm{SiH}_{4}} \alpha_{\mathrm{SiH}_{4}, \mathrm{SiH}_{4}} \alpha_{\mathrm{N}_{2}, \mathrm{SiH}_{4}} \alpha_{\mathrm{CH}_{4}, \mathrm{SiH}_{4}}^{\dagger} \alpha_{\mathrm{N}_{2}, \mathrm{SiH}_{4}}^{\dagger}$} \\
\hline $\mathrm{SiH}_{4}$ & 5.55 & 1.0 & - & - & - \\
\hline ath-Gas & $\overline{\mathscr{P}}_{a}$ & $\alpha_{a, \mathrm{SiH}_{4}}$ & $\alpha_{a, \mathrm{~N}_{2}}$ & $\alpha_{a, \mathrm{CH}_{4}}^{\dagger}$ & $\alpha_{a, \mathrm{~N}_{2}}^{*}$ \\
\hline $\mathrm{CH}_{4}$ & - & $6.8^{\ddagger}$ & - & 1.0 & 0.73 \\
\hline $\mathrm{N}_{2}$ & - & $9.2^{\ddagger}$ & - & 1.36 & 1.0 \\
\hline $\mathrm{O}_{2}$ & - & $25.8^{\ddagger}$ & - & 3.8 & 2.8 \\
\hline $\mathrm{H}_{2}$ & 648 & 117 & - & 17.1 & 12.5 \\
\hline $\mathrm{He}$ & - & $450^{\ddagger}$ & 42.7 & 66.2 & 48.6 \\
\hline${ }^{\dagger}$ From $\mathrm{P}$ & Pauly & 1999). & & & \\
\hline
\end{tabular}

factor from PAULY (1999); we are not aware of any additional data available for a comparison against the silane separation factor. The values from VOROTYNTSEV et al. (2013) are lower for all slow-permeant impurities which may indicate that the permeability of methane relative to silane may be also lower than what could be obtained with other PDMS samples. This observation is qualified by the fact that not all PDMS materials are the same and variations of the siloxane chain crosslinking can account for the difference in permeability. Note that the separation factor of methane relative to silane is small and as we will see later it is problematic; in fact the separation of oxygen, argon and hydrogen is also a concern.

The CA data (table 3.2 is limited but insightful. First, the separation factor of hydrogen relative to silane is high, and, unlike in the PDMS material, hydrogen is a fast permeant in CA. In addition, complementary data from PAULY (1999) show that other gases of interest are fast-permeant impurities relative to methane. A comparison of the results in (HSIEH AND KELLER II, 1992) for the separation of helium from nitrogen shows very good agreement with similar results from PAULY (1999), that is, $\alpha_{\mathrm{He}, \mathrm{N}_{2}}=42.7$ compared to $\alpha_{\mathrm{He}, \mathrm{N}_{2}}^{*}=48.6$; the difference could be attributed to the comparison of a (lower) effective separation factor to the ideal counterpart value for two different data sets. This leads us to assume that the data between these different sources are consistent and that taking the ratio of the values $\alpha_{\mathrm{H}_{2}, \mathrm{SiH}_{4}}=117$

Oak Ridge National Laboratory Report ORNL/TM-2016/278 pp. 1-41 
and $\alpha_{\mathrm{CH}_{4}, \mathrm{SiH}_{4}}^{*}=17.1$ allows us to estimate the separation factor $\alpha_{\mathrm{CH}_{4}, \mathrm{SiH}_{4}} \approx 6.8$ for methane from silane. Proceeding similarly, we can fill-in estimates for all other values in the $\alpha_{a, \mathrm{SiH}_{4}}$ column (table 3.2). That is, we can use the approximation $\alpha_{a, \mathrm{SiH}_{4}} \approx \alpha_{\mathrm{CH}_{4}, \mathrm{SiH}_{4}} \times \alpha_{a, \mathrm{CH}_{4}}^{*}$ for any species $a$.

Comparison of the permeability data for CA and PDMS supports the known fact that the transport mechanism on the former is diffusion based and on the latter, solubility based. Therefore these materials are complementary and probably indispensable for a full purification of silane from its common impurities. We expect the impurities with larger molecules (table 1.1) to be preferentially absorbed in PDMS, as the data seems to indicate, and rejected by CA. For instance, the Lennard-Jones force potential intermolecular parameter, $\sigma$, for the fast-permeant molecules in CA (table 3.3 are correlated with the separation factor (table 3.2.

Table 3.3: Lennard-Jones force potential intermolecular distance parameter from viscosity data (POLING et al., 2001).

\begin{tabular}{|cc|}
\hline ath-Gas & $\sigma_{a}[\AA]$ \\
\hline $\mathrm{SiF}_{4}$ & 4.880 \\
$\mathrm{C}_{2} \mathrm{H}_{6}$ & 4.443 \\
$\mathrm{C}_{2} \mathrm{H}_{4}$ & 4.163 \\
$\mathrm{SiH}_{4}$ & 4.084 \\
$\mathrm{PH}_{3}$ & 3.981 \\
$\mathrm{CO}_{2}$ & 3.941 \\
$\mathrm{CH}_{4}$ & 3.758 \\
$\mathrm{~N}_{2}$ & 3.798 \\
$\mathrm{CO}$ & 3.690 \\
$\mathrm{Ar}$ & 3.542 \\
$\mathrm{O}_{2}$ & 3.467 \\
$\mathrm{H}_{2}$ & 2.827 \\
$\mathrm{He}$ & 2.551 \\
\hline
\end{tabular}

In all cases we chose parameters to carry out a separation operation that meets or exceeds all requirements for an electronics-grade silane product. The goal of the calculations is then to compute the time needed to carry out a successful separation, given a particular choice of system parameters and an initial crude silane composition. 


\subsection{Slow-permeant impurity depletion}

A numerical example helps illuminate the formulae (section 2.2 usage as applied to a PDMS membrane. Suppose a 6 -L feed tank (fig. 2.3) is kept at 5 bar pressure and initial temperature of $25^{\circ} \mathrm{C}$ with a molar fraction $x_{\mathrm{N}_{2}}^{(\mathrm{T})}\left(t_{0}\right)=5.76 \times 10^{-4}$ which is equivalent to $576 \mathrm{ppm}(\mathrm{v})$. From (2.38), the mass of the gas mixture $\left(\mathrm{SiH}_{4}, \mathrm{~N}_{2}\right)$ is $m^{(\mathrm{T})}\left(t_{0}\right)=39.9 \mathrm{~g}$. If the final molar fraction desired in the tank is $x_{\mathrm{N}_{2}}^{(\mathrm{T})}\left(t_{f}\right)=$ $5.0 \times 10^{-7}(0.5 \mathrm{ppm}(\mathrm{v})$ per table 1.1$)$ then from (2.33), the desired purification factor is

$$
\Gamma=\frac{5.60 \times 10^{-4}}{5.0 \times 10^{-7}}=1152 .
$$

Suppose a $5 \%$, by mole, withdrawal of material can be tolerated, $\lambda=0.05$, then from (2.37) the stage impurity separation factor is $\beta=138.4$. If the permeate chamber of the membrane cell is kept at 0.1 bar then the pressure ratio is $p_{\mathrm{R}}=0.1 / 5$, and from (2.6) the effective separation factor is $\alpha_{\mathrm{SiH}_{4}, \mathrm{~N}_{2}}=3.4-0.1 / 5 \times(3.4-1)=3.35$, in view of the ideal selectivity factor $\alpha_{\mathrm{SiH}_{4}, \mathrm{~N}_{2}}^{*}=3.4$ (table 3.1). If the membrane area is $A=2.1 \mathrm{~m}^{2}$, and the membrane thickness is $h=55 \mu \mathrm{m}$, and the permeability constant $\mathscr{P}_{\mathrm{SiH}_{4}}=1.5 \times 10^{-13} \mathrm{~mol} \mathrm{~m} \mathrm{~m}^{-2} \mathrm{~Pa}^{-1} \mathrm{~s}^{-1}$ (table 3.1), then from 2.26) the retentate molar flow rate is $n^{(\mathrm{R})}=2.49 \times 10^{-6} \mathrm{~mol} \mathrm{~s}^{-1}$ driven by the trans-membrane pressure drop $\Delta p=4.9 \mathrm{bar}$. The time for performing the separation, (2.43), is then 6.74 h. From (2.44) the final temperature of the gas product in the feed tank is $40.7^{\circ} \mathrm{C}$. From 2.25) the stage cut is $\theta=0.999$ and with this in hands, 2.32 produces the recirculation factor $\gamma=1126$. That is to say, the rate of recirculating flow (fig. 2.3) is $\gamma$ times greater than the rate of withdrawal of gas into the storage tank. Finally, per 2.39) and (2.42), a $1.98 \mathrm{~g}$ of withdrawn gas is stored in the impurity storage tank with molar fraction $x_{\mathrm{N}_{2}}^{(\mathrm{S})}\left(t_{f}\right)=11510 \mathrm{ppm}(\mathrm{v})$; a substantial increase when compared to the original crude silane impurity of $576 \mathrm{ppm}(\mathrm{v})$. Note however that this is still relatively dilute, since $99.5 \%$ of the mass in the storage tank is made up of high-value, mono-isotopic silane.

The foregoing demonstrates that the desired purification of $\mathrm{SiH}_{4}$ from $\mathrm{N}_{2}$ seems very doable within the assumptions of the model and system parameters chosen. Since the stored retentate material is still dilute at $11510 \mathrm{ppm}(\mathrm{v})$, after the accumulation of a sufficient number of new runs (i.e. exactly 20 runs), the accumulated gas mixture on the storage tank could be recycled as a new feed material and further reprocessed (this could be done at a slightly higher pressure and ambient temperature to compensate for the higher level of impurity). This multi-cycle approach could significantly increase the amount of recovered material (in this example it is already high at $95 \%$ ) if the process is extended to many cycles. In addition, re-cycling can solve difficulties with impurity species that have low effective separation factors, such as $\mathrm{O}_{2}, \mathrm{Ar}$, and $\mathrm{H}_{2}$;

Oak Ridge National Laboratory Report ORNL/TM-2016/278 pp. 1-41 
more on this later.

\subsubsection{Single-cycle results}

Similar calculations (with the aforementioned parameters and membrane size), are provided (table 3.4) for slow-permeate impurity species commonly found in the silane production process, namely, $\mathrm{CH}_{4}, \mathrm{H}_{2}, \mathrm{Ar}, \mathrm{O}_{2}, \mathrm{He}, \mathrm{CO}$, and $\mathrm{N}_{2}$. The first notable fact (table 3.4) is that the separation of $\mathrm{O}_{2}, \mathrm{Ar}, \mathrm{H}_{2}$, and $\mathrm{CH}_{4}$ takes an unrealistically long time to reduce the level of impurity from crude silane to electronics-grade as theses species tend to follow silane into the permeate stream. The separation of $\mathrm{CO}$ and $\mathrm{He}$ from silane seems very doable, as $\mathrm{N}_{2}$ is.

The separation feasibility as indicated by $t_{f}$ (table 3.4) is not sensitive to the pressure applied. For instance, use of $p^{(\mathrm{F})}=10$ bar has only a relative minor reduction of $t_{f}$. We performed a simple numerical sensitivity test by varying non-geometric parameters and we have identified $\alpha_{\mathrm{SiH}_{4}, 6}^{*}$ as a critical quantity affecting the feasibility of the separation process. For the impurities of interest, an increase in $\alpha_{\mathrm{SiH}_{4}, 6}^{*}$ of $10 \%$ leads to over $70 \%$ reduction of the processing time. The origin of such an effect comes from the term $\beta^{\frac{\alpha}{\alpha-1}}$ in $(2.26)$, used in $(2.43)$, which becomes large as $\alpha$ is close to 1 and significantly smaller as $\alpha$ is greater than 2 . Therefore the measurement of the ideal separation factor, with its uncertainty, is critical for designing a successful membrane system. The model indicates that separation factors greater than or equal to 2 allow for a successful separation for the purification application we are interested (when $\beta \approx 100$ ). On the contrary, $\alpha$ leading to scalings greater than $\beta^{2}$ is not tolerable. Corresponding results (table 3.4 obtained with an operation under constant temperature lead to very similar final operation times and will not be shown. The molar flowrates computed (table 3.4) are more often needed in units of standard cubic centimeter per minute $(\mathrm{SCCM})$. The conversion factor is $1 \mathrm{SCCM}=4.45 \times 10^{-5} \mathrm{~mol} \mathrm{~min}^{-1}$, therefore the results show that measurement of the molar flowrate in the impurity storage tank is in the order of $3 \mathrm{SCCM}$; this helps select a compatible mass flow controller. It is instructive to mention that the molar flowrates for the feed and permeate streams are much higher, i.e., by a factor of $\frac{1}{1-\theta}$ and $\frac{\theta}{1-\theta}$ as given by 2.28) and (2.29), respectively; in the range of $4 \mathrm{SLM}$ (standard liter per minute). This indicates that mass

flow meters with very different scale ranges will be needed for the operation of the flow loop.

\subsubsection{Multi-cycle results}

One approach to circumvent the difficulty of separating $\mathrm{O}_{2}$, Ar, and $\mathrm{H}_{2}$, mentioned in the previous section, while still using the same membrane material (PDMS), is to employ a multi-cycle approach and change some of the control parameters such as, 
Table 3.4: Single-cycle performance quantities for slow-permeant impurity depletion loop using a PDMS membrane assuming a constant pressure ratio $p_{R}=0.02$, pressure drop $\Delta p=4.9 \mathrm{bar}$, and $5 \%$, by mole, gas mixture withdrawal, $\lambda=0.05$ (95\% material recovery). The initial temperature of the mixture is $25^{\circ} \mathrm{C}$ and final temperature, $40.7^{\circ} \mathrm{C} . x_{6}^{(T)}\left(t_{0}\right)$ is the initial impurity molar fraction, $x_{6}^{(T)}\left(t_{f}\right)$ is the desired impurity tolerance (per table 1.1). Additional information in the text.

\begin{tabular}{|c|c|c|c||c|c|c|c|}
\hline 6 th-Gas & $\mathrm{N}_{2}$ & $\mathrm{CO}$ & $\mathrm{He}$ & $\mathrm{O}_{2}$ & $\mathrm{Ar}$ & $\mathrm{H}_{2}$ & $\mathrm{CH}_{4}$ \\
\hline$x_{6}^{(\mathrm{T})}\left(t_{0}\right)\left[^{\dagger}\right]$ & 576 & 71 & 5 & 33 & 33 & 1800 & 104 \\
$x_{6}^{(\mathrm{T})}\left(t_{f}\right)\left[^{\dagger}\right]$ & 0.5 & 0.08 & 0.03 & 0.03 & 0.03 & 20 & 0.04 \\
$m^{(\mathrm{T})}\left(t_{0}\right)[\mathrm{g}]$ & 39.9 & 39.9 & 39.9 & 39.9 & 39.9 & 39.8 & 39.9 \\
$m^{(\mathrm{S})}\left(t_{f}\right)[\mathrm{g}]$ & 1.98 & 2.00 & 2.00 & 2.00 & 2.00 & 1.93 & 1.99 \\
$x_{6}^{(\mathrm{S})}\left(t_{f}\right)\left[^{\dagger}\right]$ & 11510 & 1412 & 99 & 659 & 659 & 35620 & 2079 \\
$\Gamma[]$ & 1152 & 884 & 167 & 1100 & 1100 & 90 & 2600 \\
$\beta[]$ & 138 & 133 & 101 & 138 & 138 & 89 & 154 \\
$\alpha[]$ & 3.35 & 3.09 & 2.79 & 1.73 & 1.60 & 1.49 & 1.25 \\
$\theta[]$ & 0.9991 & 0.9993 & 0.9992 & $\approx 1$ & $\approx 1$ & $\approx 1$ & $\approx 1$ \\
$\delta[]$ & 0.8779 & 0.9047 & 0.9243 & $\approx 1$ & $\approx 1$ & $\approx 1$ & $\approx 1$ \\
$\gamma[]$ & 1126 & 1388 & 1318 & $10^{6}$ & $10^{6}$ & $10^{6}$ & $10^{11}$ \\
$n^{(\mathrm{R})}\left[{ }^{\ddagger}\right]$ & 1.5 & 1.2 & 1.3 & 0.01 & 0.003 & 0.002 & $\approx 0$ \\
$n^{(\mathrm{R})}[\S]$ & 3.4 & 2.7 & 2.9 & 0.02 & 0.007 & 0.004 & $\approx 0$ \\
$t_{f}[\mathrm{~h}]$ & 6.7 & 8.3 & 7.9 & $732^{*}$ & $3111^{*}$ & $5024^{*}$ & $10^{8 *}$ \\
\hline
\end{tabular}

*Failed to meet purification level within practical time.

${ }^{\dagger}$ Molar fraction in units of $\mathrm{ppm}(\mathrm{v})$.

${ }^{\ddagger}$ Molar flowrate in units of $\mathrm{mol} \mathrm{min}^{-1} \times 10^{4}$.

$\S$ Molar flowrate in units of SCCM. 
increasing the membrane area (table 3.5), which calls for an increase in the volume of the feed tank so the priming volume of the membrane is a fraction of the total volume of the tank, and an increase of operating temperature. The idea of the multi-cycle is to break-up the purification of the full feed material into cycles where each cycle purifies a portion of the feed and recycles the retentate material at the end of a run (indicated in fig. 2.3).

As can be seen in this modified system (three cycles, table 3.5), the separation of the $\mathrm{O}_{2}, \mathrm{Ar}$, and $\mathrm{H}_{2}$ species is doable but the re-cycling option has diminishing returns with the addition of each cycle. In the example shown (table 3.5), the total operation time for purifying the crude silane with respect to the aforementioned species is $42.7 \mathrm{~h}$ with a total material recovery of $71 \%$. The remaining material is $97.9 \% \mathrm{SiH}_{4}$ by mass and it is still dilute enough to be combined with the retentate of previous (or future) runs, and used as feed material. As this combination repeats itself, with the advent of multiple new runs, a higher material recovery process will be achieved.

Another option for separating $\mathrm{H}_{2}$ (and possibly $\mathrm{O}_{2}$ and $\mathrm{Ar}$ ), for which $\mathrm{H}_{2}$ permeability data is available, is to use cellulose acetate (HSIEH AND KELLER II, 1992); this will be demonstrated with the fast-permeant impurity depletion loop (sec. 3.2).

The separation of $\mathrm{CH}_{4}$ from $\mathrm{SiH}_{4}$ is largely unrealistic with PDMS, given the data at hand. However, as it has been remarked, relatively small changes in the selectivity factor can change this result to a more attractive option. Hence, it remains to be seen whether effective separation can be achieved when rigorous permeability data is at hand. Meanwhile, the use of a cellular acetate membrane is a promising alternative (sec. 3.2 .

Additional comments are in order. Pumps and compressors rated for high-purity processing can be substantially more expensive and difficult to find than their off-shelf counterparts. The membrane cell with a $6.3 \mathrm{~m}^{2}$ area is likely to be unavailable off-shelf for immediate use with silane. The custom construction of such cell needs to avoid sealing elements that either react or contaminate the product, and more importantly the cell design must minimize the priming volume. We have assumed a small amount of silane, $40 \mathrm{~g}$, per run, contained in a relatively small feed tank $(10 \mathrm{~L})$. This gives an idea of what the priming volume of the membrane cell should be $(\approx 500 \mathrm{~mL})$ since it has to be substantially smaller than the feeding tank and tubing. Fabrication issues may arise in building a membrane with the needed surface area and low priming volume. We also have noted the range of flowrates are substantially different when comparing the retentate flow with other flows in and out of the membrane cell. The retentate flow must be carefully maintained by a mass flow controller, while the other flows can be just passively observed and recorded. The flowrate ranges are shown (table 3.5) for the retentate and feed streams. 


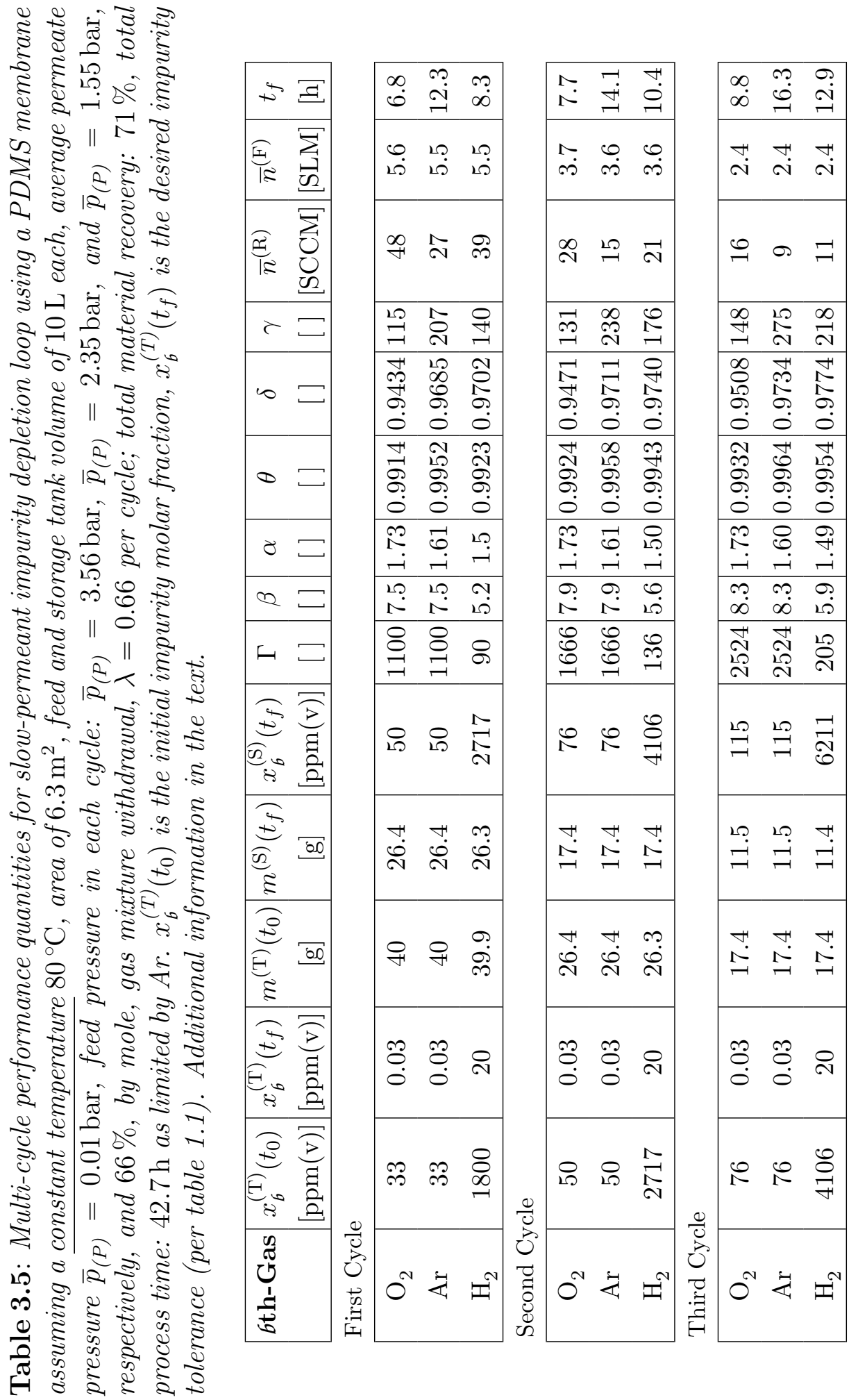

Oak Ridge National Laboratory Report ORNL/TM-2016/278 pp. 141 


\section{$3.2 \quad$ Fast-permeant impurity depletion}

Here we use the formulae presented earlier (sec. 2.3p). We begin with analyzing the performance of the CA membrane with light impurities since those are problematic with PDMS. Assuming the same system parameters as in section 3.1 we present results corresponding to table 3.4 in table 3.6 . The operation time for accomplishing

Table 3.6: Single-cycle performance quantities for fast-permeant impurity depletion loop using a CA membrane assuming a constant pressure ratio $p_{R}=0.02$, pressure drop $\Delta p=4.9$ bar, and $5 \%$, by mole, gas mixture withdrawal, $\lambda=0.05(95 \%$ material recovery). The initial temperature of the mixture is $25^{\circ} \mathrm{C}$ and final temperature, $40.7^{\circ} \mathrm{C} . x_{6}^{(T)}\left(t_{0}\right)$ is the initial impurity molar fraction, $x_{6}^{(T)}\left(t_{f}\right)$ is the desired impurity tolerance (per table 1.1). Additional information in the text.

\begin{tabular}{|c|c|c|c|c|c|}
\hline 6 th-Gas & $\mathrm{CH}_{4}$ & $\mathrm{~N}_{2}$ & $\mathrm{O}_{2}$ & $\mathrm{H}_{2}$ & $\mathrm{He}$ \\
\hline$x_{6}^{(\mathrm{T})}\left(t_{0}\right)\left[^{\dagger}\right]$ & 104 & 576 & 33 & 1800 & 5 \\
$x_{6}^{(\mathrm{T})}\left(t_{f}\right)\left[^{\dagger}\right]$ & 0.04 & 0.5 & 0.03 & 20 & 0.03 \\
$m^{(\mathrm{T})}\left(t_{0}\right)[\mathrm{g}]$ & 39.9 & 39.9 & 39.9 & 39.8 & 39.9 \\
$m^{(\mathrm{S})}\left(t_{f}\right)[\mathrm{g}]$ & 1.99 & 1.98 & 2.00 & 1.93 & 2.00 \\
$x_{6}^{(\mathrm{S})}\left(t_{f}\right)\left[{ }^{\dagger}\right]$ & 2079 & 11510 & 659 & 35620 & 99 \\
$\Gamma[]$ & 2600 & 1152 & 1100 & 90 & 167 \\
$\Theta^{*}\left[\times 10^{3}\right]$ & 5.1 & 5.9 & 6.2 & 9.8 & 8.6 \\
$\beta\left[\times 10^{3}\right]$ & 1.4 & 1.4 & 1.1 & 1.6 & 1.4 \\
$\alpha^{\prime}[]$ & 6.1 & 7.9 & 17.3 & 35.2 & 45.1 \\
$\theta[]$ & 0.73 & 0.61 & 0.34 & 0.17 & 0.14 \\
$\delta[]$ & 1.4 & 1.6 & 2.9 & 5.8 & 7.2 \\
$\gamma_{1}[]$ & 453 & 306 & 203 & 113 & 126 \\
$\gamma_{2}[]$ & 645 & 385 & 191 & 90 & 96 \\
$n^{(\mathrm{S})}\left[\left[^{\ddagger}\right]\right.$ & 0.15 & 0.29 & 0.93 & 3.7 & 4.2 \\
$n^{(\mathrm{F})}\left[{ }^{\ddagger}\right]$ & 109 & 126 & 227 & 455 & 568 \\
$t_{f}[\mathrm{~h}]$ & 151.6 & 79.8 & 24.7 & 6.2 & 5.5 \\
\hline
\end{tabular}

${ }^{\dagger}$ Molar fraction in units of $\mathrm{ppm}(\mathrm{v})$.

${ }^{\ddagger}$ Molar flowrate in units of SCCM.

the intended separation of the light impurities is now much more practical, in particular for the problematic impurities when using PDMS (table 3.4), namely, $\mathrm{O}_{2}, \mathrm{H}_{2}$, 
and $\mathrm{CH}_{4}$. In view of the size of the argon atom (table 3.3 we expect its separation performance to be in between $\mathrm{N}_{2}$ and $\mathrm{O}_{2}$, therefore all problematic light gases in the PDMS separation using the slow-permeant impurity depletion loop are better handled by the present loop using the CA membrane material. Note, however, that $\mathrm{N}_{2}$ is a much better performer in the solubility-selective PDMS membrane material (table 3.4), therefore it is not a concern when using the CA membrane material. A constant (ambient) temperature operation similar to the constant pressure operation just used (table 3.6) produces similar results and these will not be shown. A multicycle approach (similar to sec. 3.1.2 can be built to further reduce the operating time of separating $\mathrm{CH}_{4}$ by at least half the time, or more, and still produce a high material recovery; another approach is to use a multi-stage method combining different membrane materials (sec. 3.3). Before moving on to calculations for the separation of the heavy gases in PDMS, we note that in the calculation results presented in table 3.6 the separation factor values used for CA (table 3.2) were considered as ideal values. Therefore this is a conservative approach for using the estimated values since the corresponding effective separation factors are smaller as computed from (2.7). The optimal molar flowrate into the storage impurity tank, $n^{(\mathrm{S})}$, varies between 0.15 SCCM and 4.2 SCCM (table 3.6) and the corresponding optimal feed flowrate, $n^{(\mathrm{F})}=\frac{1}{1-\theta} \frac{n^{(\mathrm{S})}}{\Theta^{*}}$, is substantially higher varying from 109 SCCM to 568 SCCM respectively.

The fast-permeant impurities in PDMS are the larger molecules with higher solubility, they are collected at the bottom part of table 3.1. Using the same system parameters as before (sec. 2.3) we show results for a fast-permeant impurity depletion loop using PDMS as a membrane material (tables 3.7 and 3.8). It is observed that with the exception of ethane, diborane, and ethylene, all other fast-permeant impurities are quickly separated from silane with processing time, $t_{f}$, in the order of $1 \mathrm{~h}$. While a multi-cycle approach could be employed to further increase the efficiency of the separation, it is probably more practical to separate these larger molecules, namely, $\mathrm{C}_{2} \mathrm{H}_{6}, \mathrm{~B}_{2} \mathrm{H}_{6}$, and $\mathrm{C}_{2} \mathrm{H}_{4}$ via a mobility-selectivity strategy with $\mathrm{CA}$ as a membrane material using a slow-permeant impurity depletion cycle (sec. 3.1). In the absence of separation factor data for these species relative to silane in CA membranes, we can only speculate that since these larger molecules will be significantly slower than silane to diffuse through CA, the previously analyzed depletion loop (sec. 3.1) will likely succeed in achieving the separation. Similar to previous examples, the flowrate into the impurity storage tank (tables 3.7 and 3.8) can be as low as 3 SCCM while the retentate flowrate can be as high as 10 SLM. Hence here too, a wide range of flowrates are present and consideration needs to be given to select appropriate flowmeter devices.

It was observed before (sec. 3.1.1) that the performance of the slow-permeant impurity depletion loop depends significantly on the term $\beta^{\frac{\alpha}{\alpha-1}}(\beta>1)$, and that for $\alpha>2$ the separation results are expected to be reasonable up until $\beta \approx 100$. In contrast, the fast-permeant impurity depletion loop performance depends on the 
Table 3.7: Single-cycle performance quantities for fast-permeant impurity depletion loop using a PDMS membrane assuming a constant pressure ratio $p_{R}=0.02$, pressure

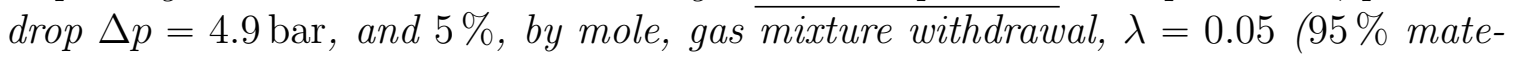
rial recovery). The initial temperature of the mixture is $25^{\circ} \mathrm{C}$ and final temperature, $40.7^{\circ} \mathrm{C} . x_{6}^{(T)}\left(t_{0}\right)$ is the initial impurity molar fraction, $x_{6}^{(T)}\left(t_{f}\right)$ is the desired impurity tolerance (per table 1.1). Additional information in the text.

\begin{tabular}{|c|c|c|c|c|c|c|c|}
\hline 6 th-Gas & $\mathrm{C}_{2} \mathrm{H}_{6}$ & $\mathrm{~B}_{2} \mathrm{H}_{6}$ & $\mathrm{C}_{2} \mathrm{H}_{4}$ & $\mathrm{CO}_{2}$ & $\mathrm{PH}_{3}$ & $\mathrm{C}_{3} \mathrm{H}_{8}$ & $\mathrm{AsH}_{3}$ \\
\hline$x_{6}^{(\mathrm{T})}\left(t_{0}\right)\left[^{\dagger}\right]$ & 22 & 5 & 22 & 0.1 & 8 & 24 & 6 \\
$x_{6}^{(\mathrm{T})}\left(t_{f}\right)\left[^{\dagger}\right]$ & 0.1 & 0.1 & 0.1 & 0.05 & 0.05 & 0.1 & 0.05 \\
$m^{(\mathrm{T})}\left(t_{0}\right)[\mathrm{g}]$ & 39.9 & 39.9 & 39.9 & 39.9 & 39.9 & 39.9 & 39.9 \\
$m^{(\mathrm{S})}\left(t_{f}\right)[\mathrm{g}]$ & 2.00 & 2.00 & 2.00 & 2.00 & 2.00 & 2.00 & 2.00 \\
$x_{6}^{(\mathrm{S})}\left(t_{f}\right)\left[^{\dagger}\right]$ & 434 & 98 & 438 & 1.1 & 159 & 486 & 119 \\
$\Gamma[]$ & 218 & 50 & 220 & 2 & 160 & 244 & 120 \\
$\Theta^{*}\left[\times 10^{3}\right]$ & 4.1 & 5.7 & 5.5 & 46.2 & 7.1 & 7.1 & 8.1 \\
$\beta\left[\times 10^{3}\right]$ & 5.3 & 7.3 & 4.0 & 25.8 & 3.0 & 2.2 & 2.6 \\
$\alpha^{\prime}[]$ & 1.8 & 1.8 & 2.4 & 3.0 & 3.7 & 5.0 & 5.0 \\
$\theta[]$ & 0.999 & 0.998 & 0.981 & 0.843 & 0.888 & 0.781 & 0.769 \\
$\delta[]$ & 1.001 & 1.002 & 1.020 & 1.181 & 1.126 & 1.280 & 1.300 \\
$\gamma_{1}[]$ & $10^{5}$ & $10^{4}$ & 4816 & 80 & 698 & 394 & 329 \\
$\gamma_{2}[]$ & $10^{5}$ & $10^{5}$ & 9386 & 131 & 1208 & 598 & 493 \\
$n^{(\mathrm{S})}\left[{ }^{\ddagger}\right]$ & 0.02 & 0.04 & 0.41 & 32.6 & 3.4 & 7.5 & 9.2 \\
$n^{(\mathrm{F})[\S]}$ & 3.8 & 3.8 & 3.9 & 4.5 & 4.3 & 4.8 & 4.9 \\
$t_{f}[\mathrm{~h}]$ & 1274 & 615 & 55.5 & 0.7 & 6.7 & 3 & 2.5 \\
\hline
\end{tabular}

${ }^{\dagger}$ Molar fraction in units of $\mathrm{ppm}(\mathrm{v})$.

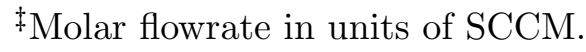

$\S$ Molar flowrate in units of SLM. 
Table 3.8: Continued from table 3.7, single-cycle performance quantities for fast-permeant impurity depletion loop using a PDMS membrane assuming a constant pressure ratio $p_{R}=0.02$, pressure drop $\Delta p=4.9 \mathrm{bar}$, and $5 \%$, by mole, gas mixture withdrawal, $\lambda=0.05$ (95\% material recovery). The initial temperature of the mixture is $25^{\circ} \mathrm{C}$ and final temperature, $40.7^{\circ} \mathrm{C} . x_{6}^{(T)}\left(t_{0}\right)$ is the initial impurity molar fraction, $x_{6}^{(T)}\left(t_{f}\right)$ is the desired impurity tolerance (per table 1.1). Additional information in the text.

\begin{tabular}{|c|c|c|c|c|c|c|}
\hline $\mathrm{C}_{3} \mathrm{H}_{6}$ & $\mathrm{H}_{2} \mathrm{O}$ & $\mathrm{n}-\mathrm{C}_{4} \mathrm{H}_{10}$ & $\mathrm{n}-\mathrm{C}_{5} \mathrm{H}_{12}$ & $\mathrm{SiCl}_{4}$ & $\mathrm{SiH}_{2} \mathrm{Cl}_{2}$ & $\mathrm{SiHCl}_{3}$ \\
\hline 22 & 0.1 & 3.1 & 7.7 & 120 & 104 & 106 \\
0.1 & 0.01 & 0.1 & 0.1 & 0.1 & 0.1 & 0.1 \\
39.9 & 39.9 & 39.9 & 39.9 & 39.9 & 39.9 & 39.9 \\
2.00 & 2.00 & 2.00 & 2.00 & 2.00 & 2.00 & 2.00 \\
438 & 1.8 & 61 & 151 & 2398 & 2078 & 2118 \\
220 & 10 & 31 & 77 & 1200 & 1040 & 1060 \\
7.5 & 18.2 & 12.3 & 10 & 6.1 & 6.3 & 6.3 \\
2.0 & 4.0 & 2.5 & 1.8 & 1.1 & 1.1 & 1.1 \\
6.2 & 13.2 & 14.5 & 23.8 & 14.5 & 19.0 & 22.5 \\
0.69 & 0.36 & 0.36 & 0.24 & 0.40 & 0.32 & 0.27 \\
1.44 & 2.75 & 2.79 & 4.13 & 2.53 & 3.17 & 3.66 \\
286 & 71 & 104 & 116 & 218 & 197 & 189 \\
392 & 68 & 99 & 99 & 217 & 180 & 166 \\
93 & 897 & 623 & 881 & 262 & 383 & 470 \\
12.5 & 121 & 84 & 119 & 35.3 & 51.6 & 63.4 \\
5.5 & 10.4 & 10.6 & 15.7 & 9.6 & 12.0 & 13.9 \\
\hline
\end{tabular}

Oak Ridge National Laboratory Report ORNL/TM-2016/278 pp. 1-41 
factor $\frac{\theta}{1-\theta} \frac{1}{\Theta} \approx \frac{\left(\beta^{-1}\right)^{\frac{1}{\alpha^{\prime}-1}}}{\Theta}$ which is a more complicated relationship for $\beta$ and $\alpha^{\prime}$ since $\Theta$ is a function of $\beta$. However, it seems for the typical values of $\beta^{-1} \approx 1000$, in our application, values of $\alpha^{\prime} \geqslant 3$ are necessary (table 3.6 and table 3.7). These observations are no substitute for a rigorous quantitative analysis based on the formulae developed here.

\subsection{Multi-stage system}

Here we look at a multi-component system with different membrane materials and combined loops for slow-permeant impurity depletion and fast-permeant impurity depletion. We show a conceptual example with four stages, all at a constant transmembrane pressure difference of 4.9 bar with variable temperature (fig. 3.1). As mentioned before (secs. 2.2 and 2.3 the disadvantage of a constant trans-membrane pressure is the increase in temperature which can reach the maximum working temperature of the membrane material.

The present results demonstrate the additional losses and time delays in this particular end-to-end purification process. We continue to use the same silane crude content as in the past examples and the same system parameters. For the constant pressure case, starting with Stage 1 (fig. 3.1) and $39.9 \mathrm{~g}$ of feed gas, the slow-permeant depletion loop using PDMS reduces the impurity levels of $\mathrm{N}_{2}$, $\mathrm{CO}$, and He below the electronics-grade standard (compare the Stage 1 product column on the left of fig. 3.1 to values in table 1.1). After leaving $1.9 \mathrm{~g}$ of $\mathrm{SiH}_{4}$ in the impurity storage tank, the remaining product mass is moved to the feed tank of the Stage 2 loop. This fast-permeant depletion loop reduces all but the $\mathrm{C}_{2} \mathrm{H}_{6}, \mathrm{~B}_{2} \mathrm{H}_{6}$, and $\mathrm{C}_{2} \mathrm{H}_{4}$ impurities, indicated on the left of the diagram (fig. 3.1. Stage 2), to levels below electronics-grade standard. Here again an additional $1.9 \mathrm{~g}$ of $\mathrm{SiH}_{4}$ is left in the impurity tank and the remaining product mass is transferred to Stage 3. Note that all of the slow-permeant impurities from Stage 1 that were not depleted to desirable levels, namely, $\mathrm{Ar}, \mathrm{O}_{2}, \mathrm{H}_{2}$, and $\mathrm{CH}_{4}$, make to the feed tank of Stage 3; their concentrations are approximately those on the left side of the diagram (fig. 3.1). Again as a reminder, the reason for the approximate qualification just mentioned is that the real gas mixture is analyzed as a mixture of individual binary mixtures. That is, in effect, say $\mathrm{CH}_{4}$ and $\mathrm{H}_{2}$ do not interfere with each other in the separation process and the concentration of these impurities, and all others, do not take into account that they are in reality all in one gas mixture. The upshot of this comment is that the levels of the calculated product impurities will be slightly higher than a real case; hence an error on the safe side. This error is expected to be small because the gas mixture is dilute.

Moving on to Stage 3, here the sieve-selective permeation is carried out with the CA membrane material. No permeability data is available for the slow-permeant im- 


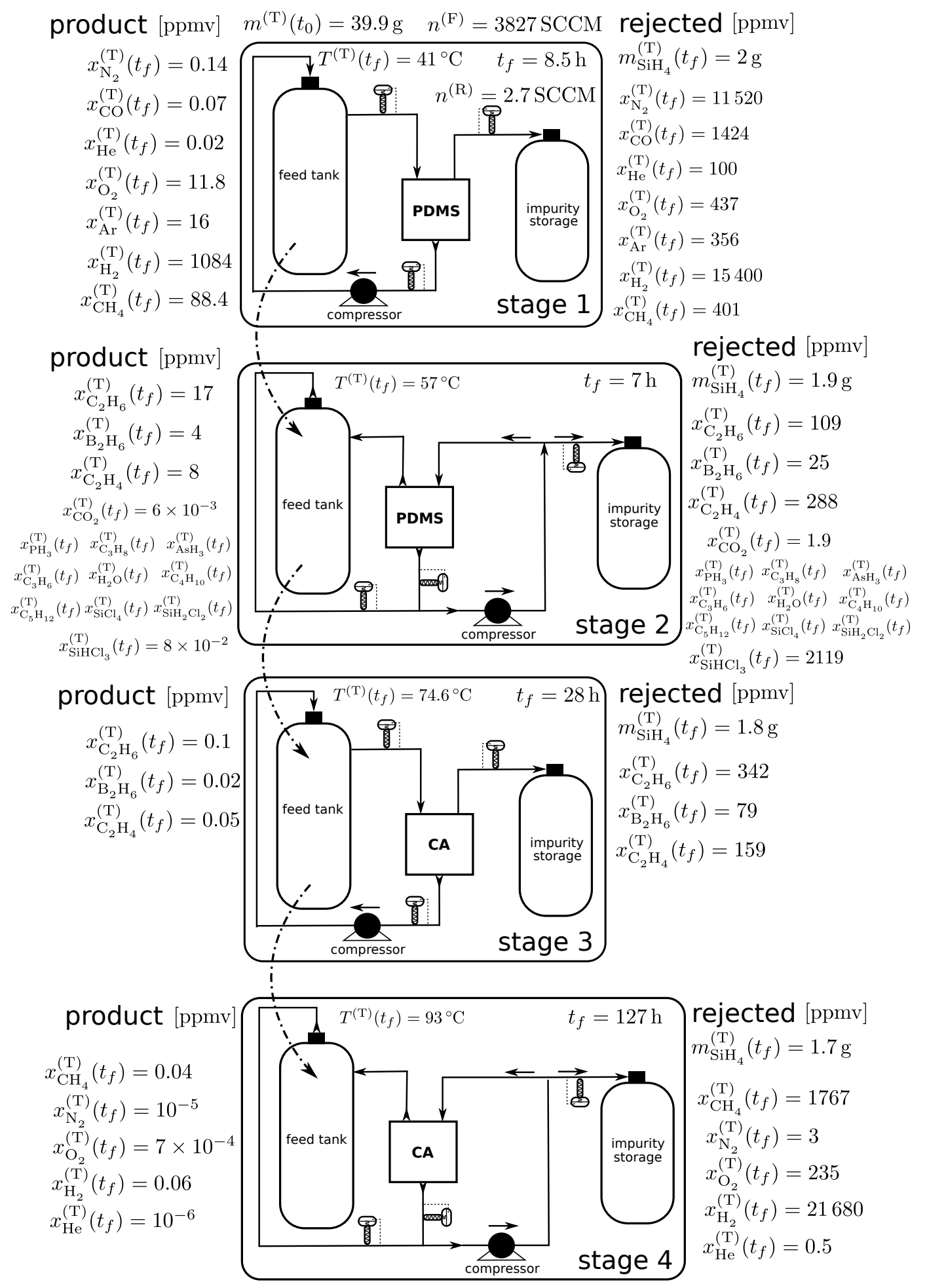

Fig. 3.1: Multi-stage impurity depletion sequence.

Oak Ridge National Laboratory Report ORNL/TM-2016/278 pp. 1-41 
purities listed in the diagram (fig. 3.1, Stage 3), therefore in the calculations presented we assume high values of separation factors for $\mathrm{C}_{2} \mathrm{H}_{6}, \mathrm{~B}_{2} \mathrm{H}_{6}$, and $\mathrm{C}_{2} \mathrm{H}_{4}$ impurities, and predict the time necessary for either meeting or exceeding electronics-grade levels (fig. 3.1. Stage 3). The temperature in this stage reaches $74.6{ }^{\circ} \mathrm{C}$ which is still acceptable for the working temperature of the CA material. In Stage 4, the final temperature reaches $93^{\circ} \mathrm{C}$ which is just slightly lower than the maximum operating temperature of AC. After $127 \mathrm{~h}$ of gas separation in Stage 4, we demonstrate that the final product either meets or exceeds the electronics-grade impurity level (fig. 3.1. Stage 4, left column) wherein the reduction of the concentration of $\mathrm{CH}_{4}$ to the needed level is the leading cause for the operation time.

\subsection{Finishing comments}

It is difficult to anticipate whether the present analysis is conservative or overoptimistic. It can be argued that there are certainly more effective ways of improving a membrane cell efficiency, hence our crossflow analysis is conservative in this respect. But on the other hand, there are other elements that can adversely affect the performance of the model described in this work that have not been taken in to consideration such as flow resistance in the membrane support layer. Also, uncertainty in the permeability values could alter the results obtained in either direction. We hope the analysis provided here helps the future design, construction, and testing of a membrane systems, where accurate data can be collected.

\section{Conclusions}

Our analysis suggests that the purification of small quantities of crude, mono-isotopic silane to electronics-grade quality is achievable via gas membrane separation based on existing permeability data published in the open literature in conjunction with mild assumptions about the data and conditions of the crude silane. In view of the difficulty of separating some of the impurity gases, notably, $\mathrm{CH}_{4}, \mathrm{H}_{2}, \mathrm{Ar}, \mathrm{O}_{2}$, $\mathrm{C}_{2} \mathrm{H}_{6}, \mathrm{~B}_{2} \mathrm{H}_{6}$, and $\mathrm{C}_{2} \mathrm{H}_{4}$, we propose the combination of membrane materials that are either sieve-selective or solubility-selective. Two such materials have been preliminary tested by other researchers, namely, cellulose acetate and polydimethylsiloxane. Although permeability data for these materials relative to silane is incomplete, our analysis indicates that the likelihood for a successful purification process based on these materials is high.

Based on the particular depletion loops we have examined, a number of combinations can be assembled between two different materials and two different flow loops. The number of combinations increase if multi-cycles are employed. The analytical 
formulae derived in this work provides the theoretical elements for studying various combinations. In particular, the equations clearly demonstrate the trade-off between different choices of parameters enabling the design path for an optimum performance. For instance, an isothermal process leads to exponential reduction of trans-membrane pressure driving force, while a constant pressure drop leads to increasing temperatures.

Emphasis should be placed in obtaining accurate permeability data for a range of conditions of temperatures and pressure. As it has been remarked, the sensitivity of the separation efficiency with respect to separation factor data is critical. Therefore an effort to measure the uncertainty of experimentally obtained permeability coefficients is a significant advantage for design purposes.

\section{Acknowledgments}

This work was partially sponsored by the U.S. Department of Energy through the Office of Science Nuclear Physics Isotope program, and the Laboratory Director's Research and Development program of the Oak Ridge National Laboratory for the U.S. Department of Energy under contract DE-AC05-00OR22725 with UT-Battelle, LLC. 


\section{A Appendix: Supporting information}

The following equation provides the molar fraction of impurity 6 in the permeate stream, $x_{b}^{(\mathrm{P})}$,

$$
x_{6}^{(\mathrm{P})}=\frac{1}{\theta n^{(\mathrm{F})}} \int_{\text {retentate port }}^{\text {feed port }} y_{6} d n .
$$

We wish to perform the integration and find the ratio 2.30 ,

$$
\delta:=\frac{x_{6}^{(\mathrm{P})}}{x_{6}^{(\mathrm{F})}},
$$

as a function of $\beta$. Using the dilute limit assumptions embodied in (2.8) and (2.6), and the assumption of a spatially constant effective separation factor of silane 2.12, the integral equation becomes

$$
x_{6}^{(\mathrm{P})}=\frac{1}{\theta n^{(\mathrm{F})}} \frac{1}{\alpha} \int_{\text {retentate port }}^{\text {feed port }} x_{6} d n .
$$

Performing the integration with the substitution of 2.18 and using $\frac{n^{(\mathrm{R})}}{n^{(\mathrm{F})}}=1-\theta$ results in

$$
x_{b}^{(\mathrm{P})}=\left.\frac{1-\theta}{\theta}\left(x_{b}^{(\mathrm{R})}\right)^{\frac{\alpha}{\alpha-1}} x_{b}^{\frac{1}{1-\alpha}}\right|_{x_{b}^{(\mathrm{R})}} ^{x_{b}^{(\mathrm{F})}},
$$

replacing the impurity mass fraction at the feed port, $x_{6}^{(\mathrm{F})}$, with the stage impurity separation factor (2.23) and continuing with applying the limits of integration gives

$$
x_{b}^{(\mathrm{P})}=\frac{1-\theta}{\theta}\left(x_{b}^{(\mathrm{R})}\right)^{\frac{\alpha}{\alpha-1}}\left(x_{b}^{(\mathrm{R})}\right)^{\frac{-1}{\alpha-1}}\left(\beta^{\frac{1}{\alpha-1}}-1\right)
$$

or

$$
\frac{x_{6}^{(\mathrm{P})}}{x_{6}^{(\mathrm{R})}}=\frac{1-\theta}{\theta}\left(\beta^{\frac{1}{\alpha-1}}-1\right) .
$$

Using the definitions (2.23) and 2.30 we get

$$
\delta=\frac{1-\theta}{\theta} \beta\left(\beta^{\frac{1}{\alpha-1}}-1\right),
$$

which reduces to the final result 2.31

$$
\delta=\frac{\beta^{\frac{\alpha}{\alpha-1}}-\beta}{\beta^{\frac{\alpha}{\alpha-1}}-1}
$$

Oak Ridge National Laboratory Report ORNL/TM-2016/278 pp. 1-41 
by employing (2.24). The faster route to this result, as mentioned previously (end of

sec. 2.1), uses the mole balance around the membrane module, $x_{6}^{(\mathrm{F})} n^{(\mathrm{F})}=x_{6}^{(\mathrm{P})} n^{(\mathrm{P})}+$

$x_{6}^{(\mathrm{R})} n^{(\mathrm{R})}$. Finally, recall the result above for $\delta$ is specific for a slow-permeant impurity.

The counterpart for a fast-permeant impurity is as in (2.64).

\section{References}

Alentiev, A., Yampolskit, Y., Ryzhikh, V., And Tsarev, D. 2013 The database "gas separation properties of glassy polymers" (Topchiev Institute): Capabilitites and prospects. Petrol. Chem. 53 554-8.

Basu, S., Kham, A. L., Cano-Odena, A., Liu, C., and Vankelecom, I. F. J. 2010 Membrane-based technologies for biogas separations. Chem. Soc. Rev. 39 $750-768$.

Bulanov, A. D., Balabanov, V. V., Pryakhin, D. A., and Troshin, O. Y. 2002 Preparation and fine purification of $\mathrm{SiF}_{4}$ and ${ }^{28} \mathrm{SiH}_{4}$. Inorg. Mater. 38 283-7.

Churbanov, M. F., Bulanov, A. D., Kotkov, A. P., Potapov, A. M., Troshin, O. Y., Lashkov, A. Y., Grishnova, N. D., and Adamchik, S. A. 2010 Production of silanes ${ }^{29} \mathrm{SiH}_{4}$ and ${ }^{30} \mathrm{SiH}_{4}$ of high chemical and isotopic purity. Dokl. Chem. 432 126-8.

Devyatykh, G. G., Dianov, E. M., Bulanov, A. D., Troshin, O. Y., BalaBANOV, V. V., AND PRYAKhIN, D. A. 2003 Preparation of high-purity monoisotopic silane: ${ }^{28} \mathrm{SiH}_{4},{ }^{29} \mathrm{SiH}_{4}$, and ${ }^{30} \mathrm{SiH}_{4}$. Dokl. Chem. $391204-5$.

Hsieh, S.-T. AND Keller II, G. E. 1992 Separation of hydrogen from silane via membranes: A step in the production of ultra-high-purity silicon. J. Membrane Sci. 70 143-52.

Itoh, K. M., Kato, J., Uemura, M., Kaliteevskit, A. K., Godisov, O. N., Devyatych, G. G., Bulanov, A. D., Gusev, A. V., Kovalev, I. D., Sennikov, P. G., Pohl, H.-J., Abrosimov, N. V., And Riemann, H. 2003 High purity isotopically enriched ${ }^{29} \mathrm{Si}$ and ${ }^{30} \mathrm{Si}$ single crystals: Isotope separation, purification, and growth. Jpn. J. Appl. Phys. 42 6248-51.

Lorenz, J. H. 1983 A survey of the preparation, purity, and availability of silanes. Report SERI/StR-211-2092, Solar Energy Research Institute, Golden, CO 80401, U.S.A. 
Majumdar, S., Heit, L. B., Sengupta, A., And Sirkar, K. K. 1987 An experimental investigation of oxygen enrichment in a silicone capillary permeator with permeate recycle. Ind. Eng. Chem. Res. 26 1434-41.

Pauly, S. 1999 Permeability and diffusion data. In J. Brandrup, E. H. Immergut, And E. A. Grulke, editors, Polymer Handbook, volume 2, chapter 6, pages 543-69. John Wiley \& Sons, Inc., Hoboken, New Jersey, fourth edition.

Poling, B. E., Prausnitz, J. M., And O'Connell, J. P. 2001 The Properties of Gases and Liquids. McGraw-Hill, Inc., New York, New York, fifth edition. first priting in 1957.

Ryzhikh, V., Tsarev, D., Alentiev, A., And Yampolskit, Y. 2015 A novel method for predictions of the gas permeation parameters of polymers on the basis of their chemical structure. J. Membrane Sci. 487 189-98.

Vorotyntsev, V. M., Drozdov, P. N., Vorotyntsev, I. V., And BalaBANOV, S. S. 2008 Membrane module with a feed tank for fine purification of gases. Theor. Found. Chem. Eng. 42 398-403.

Vorotyntsev, V. M., Drozdov, P. N., Vorotyntsev, I. V., Manokhina, S. N., AND KNysh, S. S. 2013 Fine purification of silane for removal of chlorosilanes by membrane gas separation. Petrol. Chem. 53 627-31. 